\title{
Article \\ Nascent Adhesion Clustering: Integrin-Integrin and Integrin-Substrate Interactions
}

\author{
Kuanpo Lin (D) and Robert J. Asaro *(D) \\ Department of Structural Engineering, University of California San Diego, La Jolla, CA 92093, USA; \\ kul036@ucsd.edu \\ * Correspondence: Scipio394@gmail.com; Tel.: +1-619-890-6888
}

Citation: Lin, K.; Asaro, R.J. Nascent Adhesion Clustering:

Integrin-Integrin and

Integrin-Substrate Interactions.

Biophysica 2022, 2, 34-58. https://

doi.org/10.3390/biophysica2010004

Academic Editors: Ricardo L.

Mancera, Paul C Whitford and

Chandra Kothapalli

Received: 7 December 2021

Accepted: 31 December 2021

Published: 7 January 2022

Publisher's Note: MDPI stays neutral with regard to jurisdictional claims in published maps and institutional affiliations.

Copyright: (C) 2022 by the authors. Licensee MDPI, Basel, Switzerland. This article is an open access article distributed under the terms and conditions of the Creative Commons Attribution (CC BY) license (https:// creativecommons.org/licenses/by/ $4.0 /)$.

\begin{abstract}
Nascent adhesions (NAs) are a general precursor to the formation of focal adhesions (FAs) that provide a fundamental mechanism for cell adhesion that is, in turn, involved in cell proliferation, migration, and mechanotransduction. Nascent adhesions form when cells come into contact with substrates at all rigidities and generally involve the clustering of ligated integrins that may recruit un-ligated integrins. Nascent adhesions tend to take on characteristic sizes in the range of $\mathcal{O}(100 \mathrm{~nm}-150 \mathrm{~nm})$ in diameter and tend to contain integrin numbers of $\mathcal{O}(\sim 20-60)$. The flexible, adaptable model we present provides and clear explanation of how these conserved cluster features come about. Our model is based on the interaction among ligated and un-ligated integrins that arise due to deformations that are induced in the cell membrane-cell glycocalyx and substrate system due to integrin activation and ligation. This model produces a clearly based interaction potential, and from it an explicit interaction force among integrins, that our stochastic diffusion-interaction simulations then show will produce nascent clusters with experimentally observed characteristics. Our simulations reveal effects of various key parameters related to integrin activation and ligation as well as some unexpected and previously unappreciated effects of parameters including integrin mobility and substrate rigidity. Moreover, the model's structure is such that refinements are readily incorporated and specific suggestions are made as to what is required for further progress in understanding nascent clustering and the development of mature focal adhesions in a truly predictive manner.
\end{abstract}

Keywords: nascent adhesion clusters; integrin clusters; cell adhesome

\section{Introduction}

Cells do not live alone (non solus), but instead vigorously interact with the environment which contains other cells as well as extracellular matrices (ECMs), the properties of which they sense by adhering and react to. For example, cells sense the mechanical response of their environment, e.g., stiffness [1-6] and even topography [7-10], as they proliferate [11], differentiate [2], migrate [1], as well as engage in the vital processes of cell development [12,13], including, inter alia, tumorgenesis [14,15], cell growth [16-18] and wound healing $[19,20]$, inter alia. Cells perform these functions and are so regulated via the formation of focal adhesions (FA's) [21-24] that anchor the cell either transiently (i.e., dynamically) or permanently [25,26] to, e.g., the ECM (aka the substrate); the precursor to FA's are nascent adhesion clusters as sketched in Figure 1a, that we analyze herein.

The cell's adhesion complex and its protein components, the adhesome [27,28], transmits force generated by force dependent retrograde flow and actomyosin contraction of its intracellular actin cytoskeleton (aka hereafter "actin") via a series of proteins [28-30] that are bound to each other and ultimately to the cell's extracellular matrix. In our case we consider the adhesome to utilize the plague proteins talin and vinculin; hence our force train consists of actin(myosin)-vinculin-talin-integrin-ligand (ECM/substrate) [29-31]. This is sketched in Figure 1b,c. It is, however, the initial formation of these adhesion complexes that we focus on here, viz. the formation of nascent adhesion clusters; these are described 
next, followed by our plan of study. A basic feature of these is the formation of well defined integrin clusters of, what appear to be, well regulated sized clusters containing controlled numbers of integrins of $\mathcal{O}(\sim 20-60)[32,33]$. How and why, they form and what controls their size, of $\mathcal{O}(100-150 \mathrm{~nm})$ in diameter [32,33], and integrin numbers is a main object of our study.

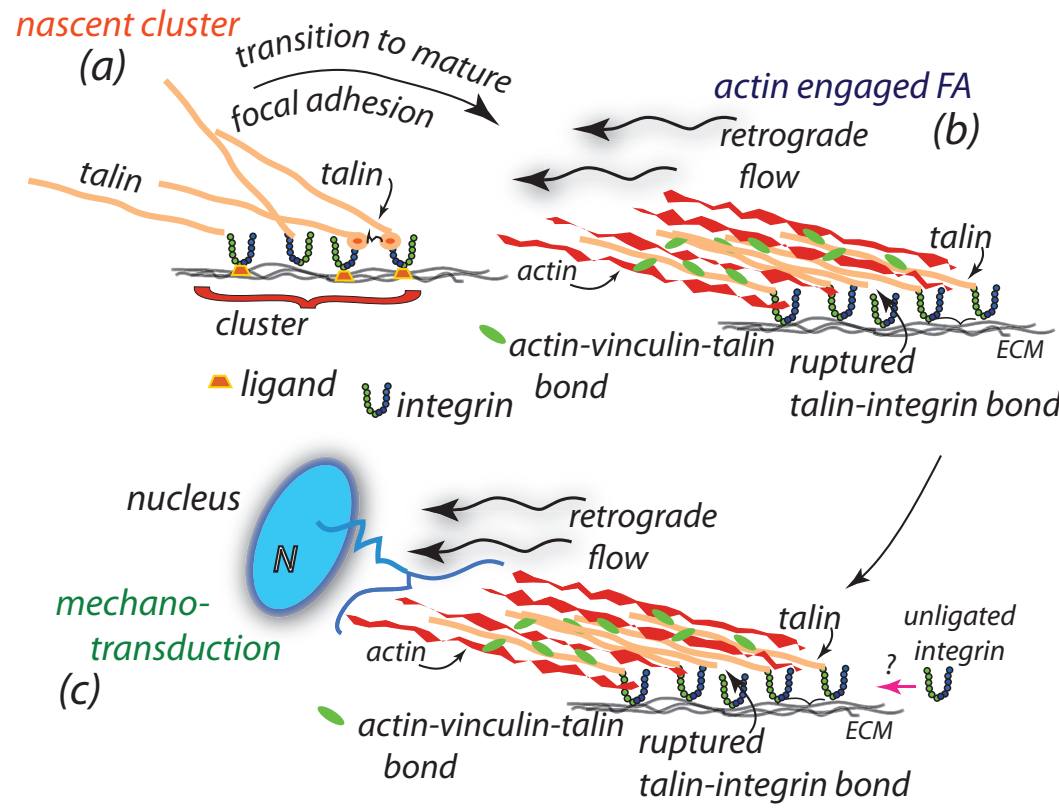

Figure 1. A rough possible scenario for the temporal pattern of imposed driving force "a" and venous slit caliber "c" vs. time. (a) The initial nascent cluster formation. (b) Cell focal adhesion. (c) Cell focal adhesion to nucleus. Note various time scales discussed in the text.

\section{Nascent Adhesion Clusters: Background}

Nascent adhesion clusters form in a step wise manner on substrates of all rigidities and do so within time scales of $\mathcal{O}(\sim 1-2 \mathrm{~min})$ [32-34]; they appear, however, to be less persistent on rigid substrates [32]. They generally attain sizes in the range of $\sim 100 \pm 30 \mathrm{~nm}$ and contain a number of integrins of $\mathcal{O}(\sim 20-60)[32,33]$ as a general rule. It is noted that clustering does not require myosin driven actin contractility as described most recently for example by Sun et al. [35], nor generally is such involved in early cluster formation [32,33,36] as indicated in Figure 1a. Integrin activation and ligation, via substrate ligands, is part of the process, yet clusters are observed to contain unligated integrins [32,33] and this requires a mechanistic explanation. It is noteworthy that clusters appear to require a minimum ligand spacing of $\mathcal{O}(\sim 60 \mathrm{~nm})$ to initiate $[37,38]$ which implies that ligated integrin interaction occurs at a distance, as in a field that decays with their separation; this interaction is, however, not short range as it appears to occur over distances of $\mathcal{O}(\geq 60 \mathrm{~nm})$, although only weakly so at larger distances. Since the integrin footprint is of $\mathcal{O}\left(\sim 42 \mathrm{~nm}^{2}\right)$, we envision, based on the elasticity solution we employ below, that the range of interaction is clearly of $\mathcal{O}\left(r_{i} \geq 2 \sqrt{42 / \pi} \approx 8-10 \mathrm{~nm}\right)$, where $r_{i}$ is the effective radius of an activated integrin. Hence, once clusters initiate, additional integrins generally join within increasing their number density.

It is interesting that Changede and Sheetz [33] hypothesize, but do not prove, that "... integrins will cluster even in the absence of bound ligands through activation by cytoplasmic proteins (e.g., talin) or $\mathrm{Mn}^{2+\prime \prime}$. The earlier findings of Cluzel et al. [36] put an overarching and finer point on the above. They reported, for $\alpha v \beta 3$ integrins on mouse melanoma cells and hamster CS-melanoma cells, that, inter alia, " $\mathrm{Mn}{ }^{2+}$ activation resulted in the formation of integrin clusters in cellular regions devoid of F-actin"; their de nova clusters formed after integrin activation with $\mathrm{Mn}^{2+}$ even after treatment with cytochalasin $\mathrm{D}(\mathrm{cD})$, i.e., after “... destruction of the actin cytoskeleton with $c D$ ". Now, immunofluorescence staining for 
talin, however, "... revealed an overlap with all clustered EGFP integrins in $\mathrm{Mn}^{2+}$-treated cells"; EGTP cells, expressing $\alpha v \beta 3$ integrins are described by Ballestrem et al. [39] who studied adhesion in similar cell lines. Consistent with absence of F-actin in de novo clusters, Cluzel et al. [36] found "... the focal adhesion adaptor proteins vinculin, paxillin, and FAK, as well as antiphosphotyrosine antibodies, did not associate with the de novo-formed clusters of activated integrins".

So far, the above observations may suggest a scenario as depicted in Figure 1a where a preliminary view is shown that is to be enhanced below. Here activated integrins, that are associated with at least talin and kindlins, tend to to cluster. We assume for now that they are recruited via their lateral mobility, i.e., by diffusion [40], to cluster from a certain initial distribution within the cell's membrane; we take this distribution to be of various types in what follows and assess the expected trends via a model simulation to be described.

Figure $1 \mathrm{~b}$ illustrates the later adhesion step where engagement with the actin cytoskeleton occurs and where force is applied via retrograde flow of the cytoskeleton; Figure 1c illustrates where manotransduction occurs via the nuclear influence felt of the adhesion's actin-vinculin-talin-integrin-substrate force train [41-43]. Before we present the first of our cluster simulation models, we add, or at least emphasize, a few finer points on nascent integrin clusters. In doing this, we focus on the interactions that integrins, in particular ligated integrins, engage in due to their distortions of the membrane-gylcocalyx-substrate system; regarding the effects of the glycocalyx per se we note that we later discuss our findings via these consideration in light of the results of Kanyo et al. [44] who studied the effects on adhesion of the glycocalyx on HeLa cancer cells by enzymatically removing the glycocalyx by systematic digestion; these results suggested to them that a mechanism involving salting-out of integrins may contribute to clustering. We discuss this suggestion by comparing the two concepts for clustering and their possible combination in Section 5, i.e., after presenting our simulation results.

\section{Finer Points Regarding the Background on Nascent Clusters}

Integrin activation has been studied extensively [45-55], most particularly with respect to the role of activating adaptor proteins, such as talin, kindlins and paxillin $[48,49,56]$ and also with regard to the potential role of integrin clustering [48]. We refer to Figure 2 for a brief discussion, and we specifically use data and observations for $\alpha_{I I I} b \beta 3$ and $\alpha v \beta 1$ integrins.

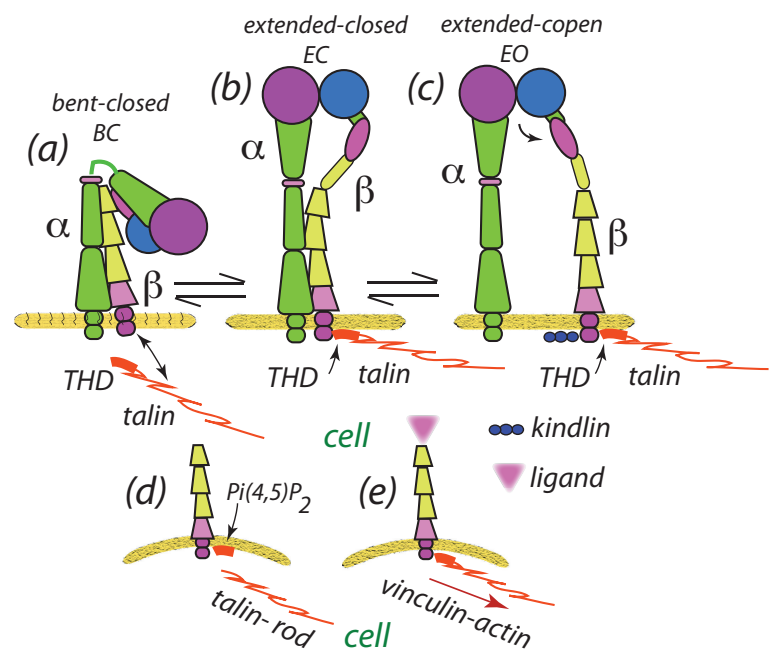

Figure 2. Three conformational states of $\alpha_{I I I} b \beta_{3}$ integrins: (a) bent closed (BC); (b) extended closed (EC); and (c) extended open (EO). In the $B C$ abd $E C$ states the $\alpha$ transmembrane domains (TM) are orthogonal to the membrane while in the $E O$ is opened [51]. Note the association (binding) of the F2 residues in the THD to acidic membrane phospholipids [57] and the association of kindlinds with the THD that supports integrin activation. (d,e) Binding of THD at the integrin $\beta$ tail, especially when the TR is re-associated with the THD, is deformed so as to develop curvature. 
The three integrin conformational states depicted are known to possess distinctly different affinity states for binding ligands $[45,48,49,51]$ where the extended open (EO) state affinity is some 5000 fold times greater than that of the bent closed $(B C)$ state [51]. Extension presents a significant barrier to activation requiring, for example, $\sim 16 \mathrm{~kJ} / \mathrm{mol}$ for $\alpha v \beta 1$ integrins [51]. Hence, in this context, we may refer to the extended states, EC and EO, as being activated $[48,49]$; roughly speaking the physical extension undergone from the $B C$ to $E O$ state is of $\mathcal{O}(\sim 10 \mathrm{~nm})$ [48]. Ye et al. [48] demonstrated that the association of the talin head domain (THD) with the $\beta$ tail of integrin is sufficient-providing integrins are embedded in a lipid bilayer and with a talin membrane binding site-to induce integrin activation; this is indicated in Figure 2b-e as explained below. Saltel et al. [57] have found that the THD binds to acidic lipids, viz. $\mathrm{PI}(4,5) \mathrm{P}_{2}$, which is part of the activation process; the participation of kindlins is discussed below. In fact, this process is facilitated by a dissociation with the talin rod (TR) which may re-associate prior to its connection to actin via vinculin; this is depicted in Figure 2d,e. Saltel et al. [57] provide interesting perspective on this. For example, they point out that one of the consequences of the THD, sine TR, binding to the intergrin $\beta$ tail "... is the absence of vinculin recruitment and uncoupling (i.e., uncoupling) from the F-actin network". They appear to argue that the membrane binding of a dissociated THD, via PI $(4,5) \mathrm{P}_{2}$ promotes clustering and then a re-association with the TR and the actin cytoskeleton. We hypothesize that may occur via the schema of Figure $2 d$,e. The THD binding will induce a membrane distortion as shown in Figure $2 \mathrm{~d}$,e; this is reminiscent of the protein membrane distortions simulated by, for example, Reynar et al. [58,59] and van der Wel et al. [60] who simulated protein clustering within lipid membranes. As described below, this provides a potential mechanism for integrin clustering; yet we point out that, unlike the case of bound capsids [58,59], the membrane distortions caused by the THD and kindlins are presumed to be rather modest and may not in themselves lead to strong clustering. On the other hand, Kim et al. [53] and more recently Gingras and Ginsberg [61] have reported that talin can change the membrane embedding topology and induce curvature and membrane thinning via integrin activation. This is due to the significant conformational changes to the $\alpha$ and $\beta$ chains that accompany activation $[50,51,61,62]$. Hence, it is not surprising that mechanical deformations are reported to promote integrin activation [63] even without talin, and Son [64] to conclude that "the formation of nascent adhesions requires the bending of the membrane toward the surface". In our simulations, the modest curvatures induced by integrin activation are modeled as a preforce, $f_{0}^{b}$, described below for various cases.

Binding of the THD to the $\beta$ tail in integrins has been described early on by Calderwood et al. [46] and Garcia-Alvarez et al. [47] and, although the applicability of what has been reviewed here to most integrins is unsettled as yet, we note that Calderwood et al. [46] had noted that "... there is general agreement that the activity of leukocyte and platelet integrins are regulated by talin, and talin-mediated activation of integrins containing $\beta 1, \beta 2$ and $\beta 3$ units has been reported in a range of cell types". We thereby will take this as a sensible basis for a basic model formulation as detailed below. At this point we turn to a brief discussion of the important role of kindlins.

The potential role of kindlin association, in collaboration with talin, must be emphasized as noted by Kammerer et al. [65] and Theodosiou et al. [56] following Calderwood et al. [49] and Bachir et al. [66]. This is discussed using Figure 3 as a guide as well as Figure 2. Kindlins co-locate with the THD at the integrin $\beta$ tail as sketched in these figures and have been implicated in integrin clustering $[56,65]$. 


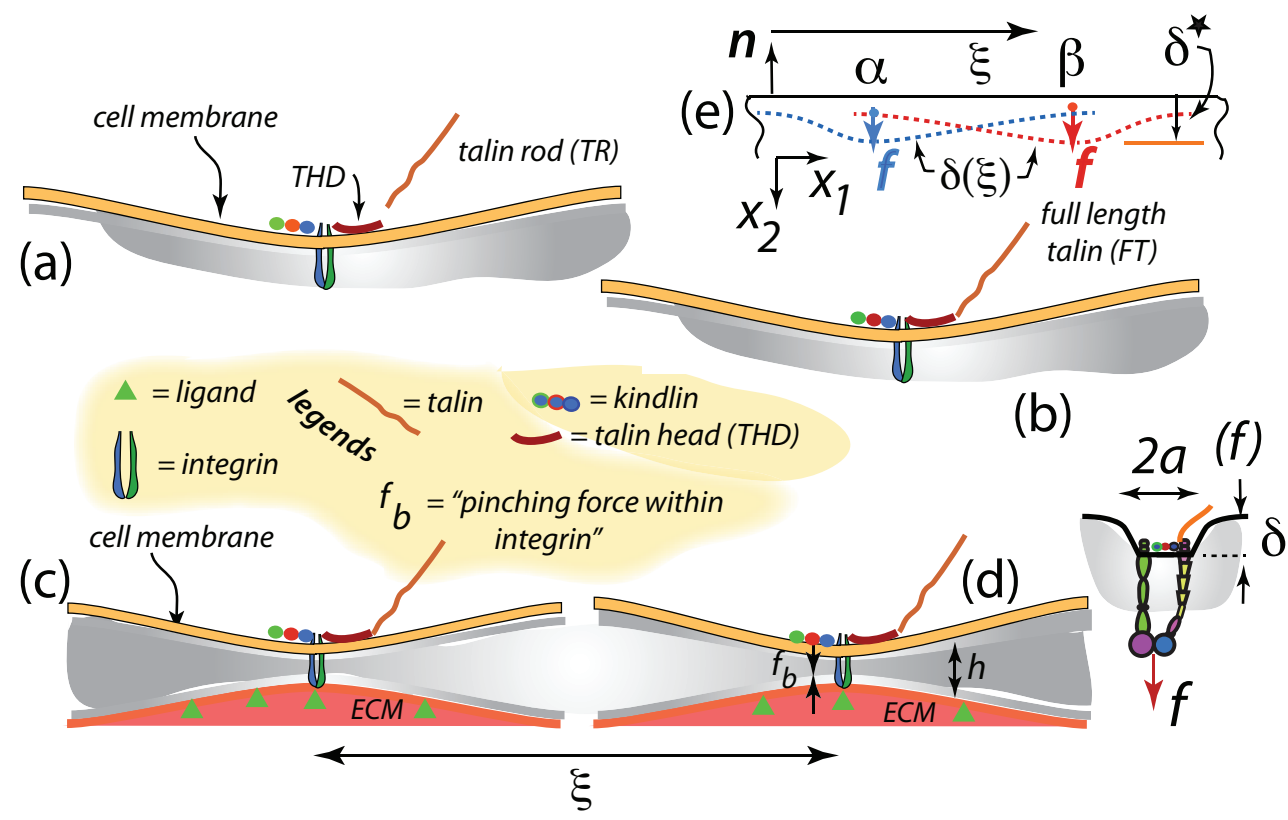

Figure 3. (a) THD and kindlins associate with the integrin $\beta$ tail causing membrane distortion. (b) TR re-associates with THD and connects to actin cytoskeleton via vinculin (shown in Figure 2c,d). (c,d) Two nearby and activated integrins, ligated or not, that interact via the deformation fields created by membrane distortion. (e) Integrins viewed as point forces, $f$, causing distortions; the distortions caused by each alone are sketched by the respective colored dashed lines. Note the displacement downward, $u_{2}(\xi)$ is called $\delta\left(\xi ; \delta_{0}\right)$ where $\delta_{0}$ is the maximum displacement beneath each point force. For a system modeled as linear elastic $\delta_{0}=1 / k f, k$ being a specific model dependent constant, and the total displacement is the linear sum of each dashed line. (f) A circular patch uniformly depressed, with a net force $f_{b}$, where $f_{b}=k \delta_{0}$ if this patch is not affected by other integrins.

Theodosiou et al. [56] have reported on a most interesting study which provides additional perspective on the role of kindlins, acting in cooperation with talin, in developing both nascent clusters and mature focal adhesions. Importantly, their study concerns $\alpha v \beta 1$ integrin expressed within mice kidney fibroblasts, demonstrating a parallel with what has been described for $\alpha_{I I I} b \beta 3$ integrins. Theodosiou et al. [56] use their observations to pose the hypothesis that "... not all integrin molecules have to be occupied by talin and therefore low levels suffice, particularly in NAs (nascent adhesions) ...". As will be seen below, our model approach is consistent with this idea and we provide a mechanistic perspective for this observation and interpretation. Theodosiou et al. [56] do state, however, “... our study demonstrates that integrin (viz. $\alpha v \beta 3$ ) affinity regulation (activation) is essential for fibroblast adhesion and depends on both talin and kindlin-2"; this supports the view of a more common function of talin and kindlins in integrin activation.

With respect to integrin activation, we note that Bachir et al. [66] have reported that whereas knidlin is recruited into nascent adhesions during their formation, talin follows in sequence just after, at least for $\alpha 5 \beta 3$ integrins in migrating $\mathrm{CHO}$ cells; the generality of this finding to other systems was unspecified. Whether this corresponds to the talin rod (TR) or talin head domain (THD) is unclear. Such a sequence, proposed for $\alpha 5 \beta 3$ integrins for this particular system, does not alter our basic scenario. Changede and Sheetz $[32,33]$ have shown that integrin ligation, although not necessarily involving all or even most integrins within a nascent cluster, is required for nascent cluster formation and that may be accomplished by the THD or kindlin as discussed above.

Still additional insight was provided by in the most interesting studies of Ye et al. [48] who studied $\alpha_{I I I} b \beta 3$ integrins embedded in liposome membranes and lipid nanodiscs bearing single or multiple embedded integrins with varying orientations protruding the nanodisc membranes. In this way they could include cases with and without the presence of ligands and thereby cases where there were no apparent cause for significant 
internal forces generated within the integrins. Ye et al.'s [48] observations using liposomes also demonstrated that, without ligands, "... there was no gross integrin clustering when THD activated $\alpha_{I I I} b \beta 3 . . . "$. Although clustering per se may not have been a focus of these studies, their observations would appear to support the view that ligand binding was required to induce clustering. However these observations, taken together with the observations of Theodosiou et al. [56], lead us to hypothesize that although clusters may require ligated integrins to form not all integrins attracted to, and incorporated within, formed clusters are ligated. We indeed suggest a reason why, and how, this may be so.

\section{Clustering Model: Outline}

We seek an essential model, with sufficient mechanistic detail, yet with optimal flexibility in that detail to readily allow for a wide range of specific model scenarios. A basis is the following, explained via the pairwise interaction of two integrins. As integrins activate, and extend, and bind to ECM ligands, they induce a deformation of the cell membrane and glycocalyx as well as possibly the ECM, if the latter should possess adequate compliance. Such deformation creates an internal force within the integrin and an elastic deformation field as sketched in Figure 3e by the colored dashed lines; the magnitude of the deformations and force depends on whether the integrin is either ligated or merely activated. Now consider the integrins in Figure $3 e$ to be modeled as "point forces", $f$, or as internal body forces, $f_{b}$, as in Figure $3 c$ acting on, or within, the cell membrane at some distance, lying at a distance $\xi=\left|\xi_{\alpha}-\xi_{\beta}\right|$ apart. The distortions sketched are thereby $\delta\left(\xi ; \delta_{0, \alpha}\right)$ where $\delta_{0}$ can be considered the displacement caused beneath a point body force acting of integrin $\alpha$ alone. Hence at the left, and right, side integrins

$$
\begin{aligned}
& \delta_{\alpha}\left(\xi ; f_{\alpha}\right)=\delta_{0, \alpha}+\delta_{\beta}\left(\xi ; f_{\beta}\right), \\
& \delta_{\beta}\left(\xi ; f_{\beta}\right)=\delta_{0, \beta}+\delta_{\alpha}\left(\xi ; f_{\alpha}\right),
\end{aligned}
$$

where $\delta_{i}, i=\alpha, \beta$ are functions of the spacing $\xi$ and $\delta_{0, i}=f_{i} / k$ where $k$ is a linear stiffness factor that is specified by the particular model used as explained below via example; $f_{i}$ is the force acting within the integrin which will depend on the pinching amount required to achieve the fixed amount of distortion. Equation (1) simply say that the net displacement beneath force $i=\alpha, \beta$ is the sum of what is produced by the prevailing force on integrin $i, f_{i}$, and what is contributed at the site of $i$ by the field of the other integrin.

Now, we assume that for an integrin, say $\alpha$, to be ligated it must create a total displacement of $\delta^{\star}$ and in that case $\delta_{\alpha}\left(\xi ; f_{\alpha}\right)=\delta^{\star}$. To be sure, when an integrin, say $\alpha$, is nearby another, say $\beta$, the internal force within it must induce an additional displacement $\delta_{0, \alpha}=\delta_{\alpha}^{\star}-\delta_{\beta}\left(\xi ; f_{\beta}\right)$; the required force in $\alpha$ is then $f_{\alpha}=k\left(\delta^{\star}-\delta_{\beta}\left(\xi ; f_{\beta}\right)\right)$; the force $f_{\alpha}$ is mitigated by the displacement $\delta_{\beta}\left(\xi ; f_{\beta}\right)$ contributed by integrin $\beta$ at the site of $\alpha$. It follows that as more integrins cluster about integrin $\alpha, \delta_{0, \alpha}$ is reduced and may indeed tend to nearly vanish; hence the internal force $f_{\alpha}=k \delta_{0, \alpha}$ reduces which provides the translational force causing integrins to cluster; in fact, if two ligated integrins were to hypothetically merge, neglecting steric constraints that would bar this, they would appear as a single point body force in terms of their elastic field.

On the other hand, to ligate an integrin must acquire energy which tends to reduce the rate, i.e., probability, of ligating; this means that integrins tend to ligate with greater rate near already ligated integrins, and in particular near clusters. We find, however, that this may be insufficient to produce well defined and sustained clusters as will be explained below.

Now considering Figure 3a,b, i.e., un-ligated integrins, we note that a similar story holds true. But un-ligated integrins should be considered mobile and hence a translational force that would bias their otherwise random diffusive motion is required. In fact, such integins would interact with each other and with ligated integrins for the reasons outlined above. This means that, given our scenario of Figure $3 a, b$, un-ligated integrins may be attracted to ligated clusters as hypothesized by Changede and Sheetz [33]. 
The effective force that attracts integrins may be uncovered by a variation in the appropriate free energy upon translation of an integrin, i.e., upon a variation in $\xi$, or more precisely in $\left|\xi_{\alpha}-\xi_{\beta}\right|$, in Figure 3e. In this, we view the forces as embedded body forces as sketched in Figure 3e. We further note that we envision that the field is determined by the fixed amount of displacement imposed at the sites of the point forces, viz. $\delta_{\alpha}^{\star}$ and $\delta_{\beta}^{\star}$. There is no surface traction involved and hence the scenario is one of fixed imposed displacement; hence the free energy is the Hemholtz free energy, viz.

$$
\mathcal{H}=\int_{v} w \mathrm{~d} v, \text { with } w=1 / 2 \sigma_{i j} e_{i j}
$$

being the strain energy density. We designate $\mathbf{x}$ to be a general spatial position vector. With $\mathbf{u}(\mathbf{x})$ being the displacement, $e_{i j}=1 / 2\left(u_{i, j}+u_{j, i}\right)$; further, the the equations of equilibrium read may be written as $\sigma_{i j, j}=-b_{i}$, with $\mathbf{b}$ being the body force density. Given the symmetry in the Cauchy stress, $\sigma$, we may further write that $1 / 2 \sigma_{i j} e_{i j}=1 / 2 \sigma_{i j} u_{i, j}=$ $1 / 2\left(\sigma_{i j} u_{i}\right)_{, j}+1 / 2 b_{i}$, the last equality holding due to the equilibrium equations. Hence $\mathcal{H}$ of Equation (2) becomes

$$
\mathcal{H}=\int_{v}\left\{1 / 2\left(\sigma_{i j} u_{i}\right)_{, j}+1 / 2 b_{i}\right\} \mathrm{d} v=\int_{s} 1 / 2 \sigma_{i j} n_{j} u_{i} d s+\int_{v} 1 / 2 b_{i} u_{i} \mathrm{~d} v,
$$

with $s$ being the bounding surface to $v$, the volume; $n$ is the outward pointing normal on $s$ to $v$. As there is no traction on $s$, the first integral vanishes and

$$
\mathcal{H}=1 / 2 \int_{v} b_{i} u_{i} \mathrm{~d} v
$$
them as

If $\xi_{\alpha, \beta}$ are the positions of integrin $\alpha, \beta$, then we may compute the force between

$$
f=-\frac{\partial \mathcal{H}}{\partial\left|\xi_{\alpha}-\xi_{\beta}\right|}=-\frac{\partial}{\partial\left|\xi_{\alpha}-\xi_{\beta}\right|} \int_{v} b_{i} u_{i} \mathrm{~d} v \text { where } i=\alpha, \beta
$$

Note that, as this reads, $f$ would be the force tending to separate them, i.e., if $f>0$ a repulsive force. Now, by stipulation the integrins are localized "point forces" and hence we take

$$
b_{\alpha, \beta}=f_{\alpha, \beta}=k\left\{\delta_{\alpha, \beta}^{\star}-\delta_{\beta, \alpha}\left(\left|\xi_{\alpha}-\xi_{\beta}\right|\right)\right\} \delta\left(x-\xi_{\alpha, \beta}\right),
$$

where the Dirac functions, $\delta\left(x-\xi_{\alpha, \beta}\right)$, localize the point forces at positions $\xi_{\alpha, \beta}$. Next, Equation (6) is substituted into Equation (5) where we note that the integration over volume $v$ is over the variable $\mathbf{x}$, to obtain

$$
f_{\alpha \leftrightarrows \beta}=f=\frac{1}{2}\left\{\left.f_{\alpha}^{\star} \frac{\partial \delta_{\beta}}{\partial\left|\xi_{\alpha}-\xi_{\beta}\right|}\right|_{\alpha}+\left.f_{\beta}^{\star} \frac{\partial \delta_{\alpha}}{\partial\left|\xi_{\alpha}-\xi_{\beta}\right|}\right|_{\beta}\right\},
$$

where $f_{\alpha, \beta}^{\star}=k \delta_{\alpha, \beta}^{\star}$. To be sure, a term such as $\partial \delta_{\beta} /\left.\partial\left|\xi_{\alpha}-\xi_{\beta}\right|\right|_{\alpha}$ represents the rate of change of displacement caused by the $\beta$ integrin at the site of the $\alpha$ integrin with respect to the absolute magnitude of their distance, $\left|\xi_{\alpha}-\xi_{\beta}\right|$; as this is negative, the force tending to separate the integrins is negative, since $f_{\alpha}^{\star}>0$. This means, in turn, that the integrins attract.

For an integrin that is ligated, or attempting to do so, its internal force would be computed from Equation (6), neglecting the Dirac functions of course. Ligated integrins are assumed to have limited mobility, yet for un-ligated integrins the interaction force is important in that it biases diffusion in favor or clustering. Un-ligated integrins are biased toward ligated integrins where the internal force required for ligation is reduced and hence the rate, i.e., the probability, of ligation is enhanced. 


\subsection{Specific Integrin Elastic Model}

We propose a simple model for an integrin as sketched in Figure $3 \mathrm{f}$ where the uniform indentation of $\delta^{\star}$ is induced within a circular patch of radius $r=a$. The pressure under such an uniform indentation is $p(r)=p_{0} /\left(1-(r / a)^{2}\right)^{1 / 2}$; the net force, as pictured as $f$ in Figure $3 \mathrm{e}$, is $f=2 \pi a^{2} p_{0}$ [67]. The solution for the displacement field outside of the patch is given by Johnson [67] as

$$
\begin{gathered}
\delta(\xi)=\frac{2\left(1-v^{2}\right) p_{0} a}{E} \sin ^{-1}\{a / \xi\}, \text { for } a / \xi \geq 1, \text { or } \\
\delta(\xi) \approx \frac{\left(1-v^{2}\right) f}{\pi E} \frac{1}{\xi} \text { for } a / \xi \geq 2 \\
f_{\alpha, \beta}^{\star}=\frac{\pi a E}{1-v^{2}} \delta_{\alpha, \beta}^{\star} \longrightarrow k=\frac{\pi a E}{1-v^{2}} .
\end{gathered}
$$

These relations are used in Equation (7) to compute the interaction force and define the stiffness factor, also of Equation (7). In what follows we take $a=3 \mathrm{~nm}$ to account for the integrin footprint of $42 \mathrm{~nm}^{2}$ [33] and the co-location of kindlin and the THD. As an estimate for integrin stretching, i.e., $\delta^{\star}$, we will generally take $\delta^{\star} \sim 10 \mathrm{~nm}$ When considering ligation, $\delta^{\star}$ will include the need to deform the cell membrane and glycocalyx and will be larger; in those cases $\delta_{\alpha, \beta}^{\star}=\delta_{\ell}^{\star}$, where subscript " $\ell$ " signifies ligation. To gain perspective on this numerology, we estimate the magnitude of $f$ from Equation (8); we set $a / \xi=1$ and with various values of $E$, and with $v=1 / 2$, we obtain

$$
f=\left\{\begin{aligned}
0.625 \mathrm{pN}, & E=5 \mathrm{kPa} \\
1.25 \mathrm{pN}, & E=10 \mathrm{kPa} \\
2.50 \mathrm{pN}, & E=20 \mathrm{kPa}
\end{aligned}\right.
$$

With $E=5 \mathrm{kPa}$ and $a=3 \mathrm{~nm}$, for example, we obtain $k=6.28 \times 10^{-5} \mathrm{Nm}^{-1}=$ $6.28 \times 10^{-2} \mathrm{pNnm}^{-1}$. These numbers provide only a quite general, hopefully better than order of magnitude, perspective on the level of force generated within integrins.

\subsection{Simulation Model: General Set Up}

The basic simulation model can be outlined using Figure 4 where integrins in their three states are indicated. Note that here we assume a certain initial population of integrins and not that integrins are introduced in pre-clusters, say for example, from deposition from released integrin carrying vesicles [68,69]. Un-activated and activated yet un-ligated integrins are considered mobile and freely diffuse within the membrane.

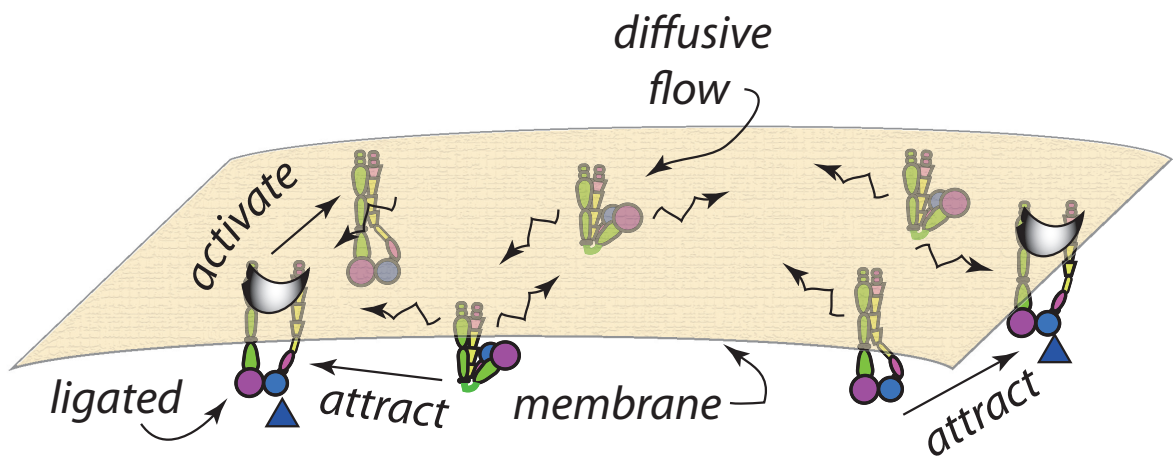

Figure 4. General set up for a diffusion based integrin clustering based on interactive integrins. Ligated integrins are relatively immobile, possessing very small diffusivity, whereas active yet unligated integrins are mobile, with finite diffusivity. Inactive integrins are mobile but do not interact with either ligated or unligated active integrins. The broken arrows indicate finite diffusiveness whereas the solid arrow indicates attractive interaction. 
Activated integrins, associated with kindlins and the THD, however interact with ligated integrins that are considered either immobile or of significantly reduced mobility. The attraction force is computed by Equation (7). Ligation of activated integrins occurs with a probability, that translates to a rate, that depends on the energy associated with achieving an indentation of $\delta_{\alpha, \beta}^{\star}$; we take this, as noted above, to be such that $\delta_{\alpha, \beta}^{\star} \approx 10 \mathrm{~nm}$. But if ligation is to occur near an already ligated integrin, say integrin $\alpha$, the additional indentation is reduced to $\delta_{\ell}^{\star}-\sum_{\{\eta\}} \delta_{\beta}\left(\left|\xi_{\alpha}-\xi_{\beta}\right|\right)$ where $\{\eta\}$ is the set of all activated integrins not including $\alpha$; thus ligation is favored near an existing ligated integrin and clusters of ligated integrins. Note that the above schema does promote the incorporation of un-ligated, and particularly activated, integrins into clusters as suggested by Changede and Sheetz [33].

Let the set of all ligated integrins be called $\left\{\eta_{\ell}\right\}$, the set of activated but un-ligated integrins be $\left\{\eta_{u \ell}\right\}$, and the union be $\{\eta\}=\left\{\eta_{\ell}\right\}+\left\{\eta_{u \ell}\right\}$. The embedded body forces within integrins are determined as follows:

$$
\begin{gathered}
\delta_{0, \alpha}\left(f_{\alpha}\right)+\sum_{\beta=\{\eta\}} \delta\left(\left|\xi_{\alpha}-\xi_{\beta}\right|, f_{\beta}\right)=\delta^{\star}, \delta_{0, \alpha} \geq 0 ; \alpha \in\left\{\eta_{\ell}\right\} \\
\delta(0, \alpha)=\delta_{u \ell}^{\star}, \alpha \in\left\{\eta_{u \ell}\right\} \text { and then } \\
f_{\alpha}=k \delta_{0, \alpha}, \alpha \in\left\{\eta_{\ell}\right\}+\left\{\eta_{u \ell}\right\} .
\end{gathered}
$$

We note, for clarity, that for unligated integrins what is specified is a fixed $\delta_{u \ell}^{\star}$ and hence for an unligated integrin $f_{\alpha}^{u l}=k \delta_{u \ell}^{\star}$ regardless of the displacement fields of other integrins; i.e., unligated integrins simply cause a fixed indentation.

\subsection{Simulation Model: Force Mediated Diffusion}

For diffusive motion we take the mean square particle distance traveled, in time $t$, to be $\left\langle r^{2}\right\rangle=4 D t^{\gamma}$, where $D$ defines a diffusion coefficient and, for free diffusion, $\gamma=1$ [70]. For viscous motion, with velocity $v$, under an applied force we take a linear relation $v=1 / \zeta f$; the Stokes-Einstein relation [70] provides the link, as

$$
1 / \zeta=D / k T .
$$

We apply a general scheme to simulate particle diffusive-ballistic motion patterned after Brànka and Heyes [71]; here $x_{i}, i=1,2$ are the 2D coordinates of particle, i.e., integrin, $i$.

To simulate $2 \mathrm{D}$ diffusion per se, we write that

$$
\frac{d x_{i}}{d t}=\dot{x}_{i}=D^{1 / 2} \phi_{i}, i=1,2 \text { and with expectation }\left\langle\phi_{i}\right\rangle=0 .
$$

Here $\phi_{i}$ is a random force that contains $k T$ and $D^{1 / 2}$ as scaling factors, explained below. When Equation (12) is integrated over a short time (step) $\Delta t$ we obtain

$$
x_{i}=D^{1 / 2} \phi_{i} \Delta t, i=1,2 \text {, with again }\left\langle\phi_{i}\right\rangle=0 .
$$

Hence, we may take $x_{i}=W_{i}$, with $\left\langle W_{i}\right\rangle=0$. But given that $\left\langle r^{2}\right\rangle=\left\langle x_{1}^{2}+x_{2}^{2}\right\rangle=4 D t$, we find

$$
\left\langle W_{i}^{2}\right\rangle=2 D t, i=1,2 \text {. }
$$

Now the general equations of motion read

$$
\dot{x}_{i}=\frac{1}{\zeta} f^{(i)}+D^{1 / 2} \phi_{i}
$$

and hence, using a Runge-Kutta order 2 integrator, we arrive at the explicit iteration

$$
x_{i, n+1}^{(\alpha)}=x_{i, n}^{(\alpha)}+\frac{1}{2}\left\{\tilde{f}_{i}^{(\alpha)}\left(t_{n}, x_{n}\right)+\tilde{f}_{i}^{(\alpha)}\left(t_{n+1}, x_{n+1}^{\alpha, E}\right)\right\}+W_{i}, i=1,2, \alpha=\left\{\eta_{a}\right\},
$$


where $\tilde{f}_{i}^{(\alpha)}=1 / \zeta f_{i}^{(\alpha)}$ is the normalized $i^{t h}$ component for interaction force computed from Equation (7), when summed over all integrins that produce an elastic field and

$$
x_{i, n+1}^{\alpha, E}=\tilde{f}_{i, n}^{(\alpha)} \Delta t+W_{i}, i=1,2
$$

is the "Euler" estimate of $x_{i}$ at time $t_{n+1}=t_{n}+\Delta t$.

\subsection{Ligation vs. Bond Rupture Kinetics}

We adopt a simple approach to describe the rate of ligation and ligation bond rupture, viz. we write that

$$
k_{\text {on }}=k_{\text {on }}^{0} e^{-\phi},
$$

where

$$
\phi=\left\{\begin{array}{ll}
f\left\{\delta^{\star}-\bar{\delta}_{\beta}\right\} / k T, & \bar{\delta}_{\beta} \leq \delta^{\star} \\
0, & \bar{\delta}_{\beta}>\delta^{\star},
\end{array}\right. \text { and }
$$

$f$ is the force that would develop within the integrin as it ligates; ligation involves 2 length scales, viz. $\delta^{\star}$ and $\bar{\delta}_{\beta} . \bar{\delta}_{\beta}$ is used here to denote the net displacement at the ligating integrin caused by the displacement fields of all other integrins-i.e., all that have such fields-and $\delta^{\star}$ is the total displacement required for ligation; $\bar{\delta}_{\beta}$ is given as

$$
\bar{\delta}_{\beta}=\sum_{\beta=\{\eta\} \bar{\alpha}} \delta_{\beta} \text {, where }
$$

$\{\eta\}_{\bar{\alpha}}=\left\{\eta_{\ell}\right\}+\left\{\eta_{u l}\right\}-\alpha$. To be sure, we have

$$
f=k\left\{\delta^{\star}-\sum_{\beta=\{\eta\}_{\bar{\alpha}}} \delta_{\beta}\right\} .
$$

This approach is equivalent to that adopted by, e.g., Sun et al. [35,72] that followed the observations of Erdmann and Schwarz [73] who analyzed the effects of integrin-ligand separation on cluster formation and and stability. Both approaches leaned heavily on the ad hoc formalism of Bell [74,75]. Effectively, the approach assumes that the rate of ligation is mediated by an activation energy, $\Delta \mathcal{G}_{\text {act }}^{\ell}$, that depends on $f$, an internal force on the integrin that opposes integrin extension. This may be written as $\Delta \mathcal{G}_{\text {act }}^{\ell}=\Delta \mathcal{G}_{\text {act }}^{0, \ell}+\Delta \mathcal{G}_{\text {ext }}^{\ell}$, where $\Delta \mathcal{G}_{\mathrm{ext}}^{\ell} \sim$ work of extending the integrin, including deforming the cell membrane-glycocalyx$E C M$ system; the latter is related to $f$ and $\delta^{\star}$ as $\Delta \mathcal{G}_{\mathrm{ext}}^{\ell} \sim \gamma f \delta^{\star}, \gamma$ being determined by the particular model used to relate $f$ to $\delta^{\star}$. Hence we arrive at Equation (18) with Equation (19). In this, $k_{\text {on }}^{0}=\mathcal{K}^{\circ} \exp \left\{-\mathcal{G}_{\text {act }}^{0, \ell} / k T\right\}$, and $\mathcal{G}_{\text {ext }}^{0, \ell}$ represents the additional work of extension involving the system stiffness; $\mathcal{K}^{\circ}$ is a kinetic pre-factor.

To rigorously describe the kinetics of bond rupture, i.e., unligation, we should account for the catch-bond nature of integrin-ligand bonding via computing bond survival times [76]; a particularly clear and implementable theory for this has been presented by Thomas et al. [77,78] and has been implemented for adhesion by Asaro et al. [79]. However, in simulations such as the ones we pursue here such an implementation would distract us from the salient points to be made in employing a matrix of parameter studies and would require detailed knowledge of data on catch-bond properties that are rarely available. Hence we take an alternate route to approximate this by drawing from the somewhat ad hoc formalism developed by Bell and co-workers [74,75]. Bell's formalism has, indeed been used in this context by others, e.g., [72,80-82]. Toward this end we write

$$
k_{\text {off }}=k_{\text {off }}^{0} e^{\varphi},
$$

where

$$
\varphi= \begin{cases}3 f / f_{\max }, & \delta^{\star}-\delta \geq 0 \\ 0, & \delta^{\star}-\delta<0\end{cases}
$$


and where $f_{\max }=k \delta^{\star}$. This is often said to be a simple slip-bond whose rupture rate is monotonically increased by a force like $f$.

Integrin-ligand bonds are generally described using a two-state energy landscape as suggested by the two extended states for activated integrins sketched in Figure 2; specifically they are described as catch-bonds [76-78]. As noted above, we use a simpler description in the current case due to the quite limited range of force level imposed on the integrin-ligand bonds. Data for such kinetics, e.g., for $k_{\mathrm{on}}^{0}$ and $k_{\mathrm{off}}^{0}$ however, remains both elusive and disparate, since parameter values have been determined for various systems without the context of the present cell adhesion. We have chosen values that are reported, and used in analysis, by a range of studies [72,80-85] and tended to use median values that are listed with our case studies. Variations of these have been utilized to establish sensitivity.

\subsection{Scaffolding Proteins Affect Clustering: Talin}

Scaffolding proteins such as talin bind to integrins and promote activation and ligation as described via Figures 1 and 2. In fact, Changede and Sheetz [32,33] in their overview reports have proposed that [33] "... the (talin) rod domain contains an integrin binding site 2(IBS2) required for clustering, which directly binds the activated $\beta$ subunit of the integrin domain ..." as sketched in Figure 2e. We have included this into our modeling by specifying a probability of binding of talin rod (TR) to ligated integrins and, in turn, the binding of unligated integrins to integrin-talin complexes; such unligated integrins, with reduced mobility, are referred to as "unligated+tailin" in our subsequent example simulation figures. We take a simple approach to describing these effects of talin by noting first that binding of talin to an integrin, say an unligated integrin via a vinculin catch-bond [79] would most likely unjustified and hence a simpler approach is required to capture the main effects of restricted mobility due to both bonding and corralling effects of the scaffolding network. Hence we take the view that an unlighted integrin that migrates within a certain distance, $r_{\text {talin, }}$ of a ligated integrin experiences a reduced mobility ascribed by $D_{\text {unligated-talin; }}$ these reduced diffusion coefficients are listed in our case studies to follow, where $r_{\text {talin }}$ is typically taken in the range $15 \mathrm{~nm} \leq r_{\text {talin }} \leq 25 \mathrm{~nm}$. Hence in our simulations we allow such restricted integrins to move by diffusion and viscous drag albeit with reduced mobility; the effect is they are "encouraged to cluster", yet can move out and become free again, or they may ligate with enhanced probability due to the proximity of nearby ligated, and perhaps clustered, integrins. Our case studies illustrate ample examples of such choices.

\section{Results}

\subsection{Effects of Parameters}

We begin with a few pointed observations concerning the anticipated effects of key parameters on potential clustering. Specifically, we comment on expected effects of integrin ligation distance, $\delta_{\alpha, \beta}^{\star}$, diffusion coefficient, $D$, and cell membrane-substrate stiffness, $E$. For $\delta_{\alpha, \beta}^{\star}$, hereafter simply referred to as $\delta_{\ell}^{\star}$, we first recall that the extensional distance of an activated integrin is of $\mathcal{O}(10-12 \mathrm{~nm})$, hence $\delta^{\star} \geq 10 \mathrm{~nm}$. On the other hand, integrins must extend beyond the cell's gycocalyx whose thickness is of $\mathcal{O}(10-60 \mathrm{~nm})$, or thicker [86-89]; hence in our simulations we explore the range $10 \mathrm{~nm} \leq \delta_{\ell}^{\star} \leq 60 \mathrm{~nm}$. For diffusion coefficients, we note that integrin diffusive mobility has been studied in a number of contexts related to adhesion, including those specifically related to clustering, e.g., [90-93]; based on these reports, we may assume $10^{-15} \mathrm{~m}^{2} \mathrm{~s}^{-1} \leq \mathrm{D} \leq 5 \times 10^{-13} \mathrm{~m}^{2} \mathrm{~s}^{-1}$; in our case studies, however, we take $D \leq 2 \times 10^{-14} \mathrm{~m}^{2} \mathrm{~s}^{-1}$. In a most interesting study of integrin mobility within FAs, Rossier et al. [93] reported variable diffusion coefficients for $\alpha_{v} \beta 3$ and $\alpha 5 \beta 1$ integrins that depended on the state of confinement within the adhesion; integrins were defined as being "free" when they were outside FAs and unligated and "immobilized" when they were ligated and bound to actin binding proteins (ABSs) such as talin. For ligated and ABS bound integrins we generally take $D=D_{\ell \mathrm{ig}}=10^{-18} \mathrm{~m}^{2} \mathrm{~s}^{-1}$ $10^{-16} \mathrm{~m}^{2} \mathrm{~s}^{-1}$ to make our model adaptable; with this low value, however, we confirmed that there were no perceptible differences than when simply assigning $D_{\ell \mathrm{ig}}=0$. For free 
integrins Rossier et al. [93] report that $D_{\text {free }} \sim 7 \times 10^{-14} \mathrm{~m}^{2} \mathrm{~s}^{-1}$; we generally chose values between $D=10^{-15} \mathrm{~m}^{2} \mathrm{~s}^{-1}-2 \times 10^{-4} \mathrm{~m}^{2} \mathrm{~s}^{-1}$ to be more consistent with with a range of reports as already cited [90-93]. In an exploratory simulation, presented in Section 4.2.1, we take $D=10^{-17} \mathrm{~m}^{2} \mathrm{~s}^{-1}$ to consider a case of cells supported on supported lipid bilayers (SBLs) with mobile ligands that allowed for ligated integrin diffusion [32]. With this we anticipate and explore the following, inter alia, effects.

1. Ligation distance, $\delta_{\alpha, \beta}^{\star} \underset{\text { called }}{\stackrel{\text { generically }}{\longrightarrow}} \delta_{\ell}^{\star}$ : As the force, $f$, within an integrin depends on $\delta^{\star}$, as does the integrin's displacement field, we expect this parameter to have a first order effect on integrin migration and ligation binding lifetime. These effects are, however, complex due to the cooperative nature of integrin interaction as well as the stochastic nature of integrin migration and ligation and un-ligation behavior. We further note that the interaction forces are related to combinations of terms such as $f \partial \delta / \partial \xi$ as in Equation (7), and as $f \sim E \delta_{\ell}^{\star}$ and $\partial \delta / \partial \xi \sim 1 / E \delta_{\ell}^{\star}$, the interaction force between integrins may be expected to dominated by $\left\{\delta_{\ell}^{\star}\right\}^{2}$. However, as the internal force, $f$, depends on $E$, the rate of un-ligation will depend directly on stiffness $E$. Hence the effects of $E$, per se, are not easily anticipated a priori. For example, due to the attractive forces among the integrins we expect that increased mobilities will tend to reduce time scales for cluster formation and perhaps affect cluster size.

2. Integrin diffusion coefficient, $D$ : Both the rate of diffusion and viscous motion depend on the magnitude of $D$ since the viscous mobility, $1 / \zeta$, and $D$ are related as $1 / \zeta=D / k T$. Hence we expect that $D$ will have a first order effect in promoting clustering.

3. Cell membrane-substrate stiffness, $E$ : The effect of stiffness has already been noted and we expect that its main effect will be in determining whether clusters are stable or not; this is expected due to the effect of large integrin internal forces on the rate of un-ligation, i.e., $k_{\text {off }}$. In terms of interaction force, the effect of $E$ becomes more difficult to anticipate in such a stochastic process as diffusion-interaction driven clustering. Hence, we might say "we'll see what happens and try to rationalize after".

For additional perspective on the meaning and value of the results to be discussed, we note that they will show the influence of specific system parameters that are not typically reported, or perhaps even known for a given cellular system where clusters have been observed. Hence, the value of models of this type is to point to those physical parameters that require documentation if analysis of clustering events is to be possible.

\subsection{Simulation Results}

To begin, we recall the observations of Ye et al. [48] who reported that no "gross clustering" of integrins was observed in the absence of binding to ligands, this lack of ligation they achieved by incorporating $\alpha I I I b \beta 3$ into liposomes with activation with the THD. To explore this, as mentioned in Section 2, we performed simulations that mimicked this case by simply precluding ligation, as if ligands were absent; Figure 5 displays some results in which we explore two levels of $\delta_{u \ell}$ and integrin mobility, i.e., $D$.

Cases \#1 and \#3 of Figure 5 specify $\delta_{u l}^{\star}=1.6 \mathrm{~nm}$ and $3.2 \mathrm{~nm}$, respectively; this, in turn, sets $f_{0}^{b}=0.1 \mathrm{pN}$ and $0.2 \mathrm{pN}$, respectively. There is, evidently, little or no tendency towards forming clear distinct clusters despite the mutual pairwise attraction of these active but unligated integrins as described by Equation (7). We also increased $D$ from $D=10^{-15} \mathrm{~m}^{2} \mathrm{~s}^{-1}$ to $D=2 \times 10^{-14} \mathrm{~m}^{2} \mathrm{~s}^{-1}$ to test the sensitivity to mobility and observed no discernable differences. Given the physical origins of the pre-force, $f_{0}^{b}$, and its relation to its "driver", $\delta_{u \ell}^{\star}$, we do not believe that larger values are physically relevant. Hence, these results appear to be consistent with both the observations of Ye et al. [48] and Changede and Sheetz $[32,33]$ regarding the need for, at least some, integrins to be ligated to form distinct nascent clusters. 

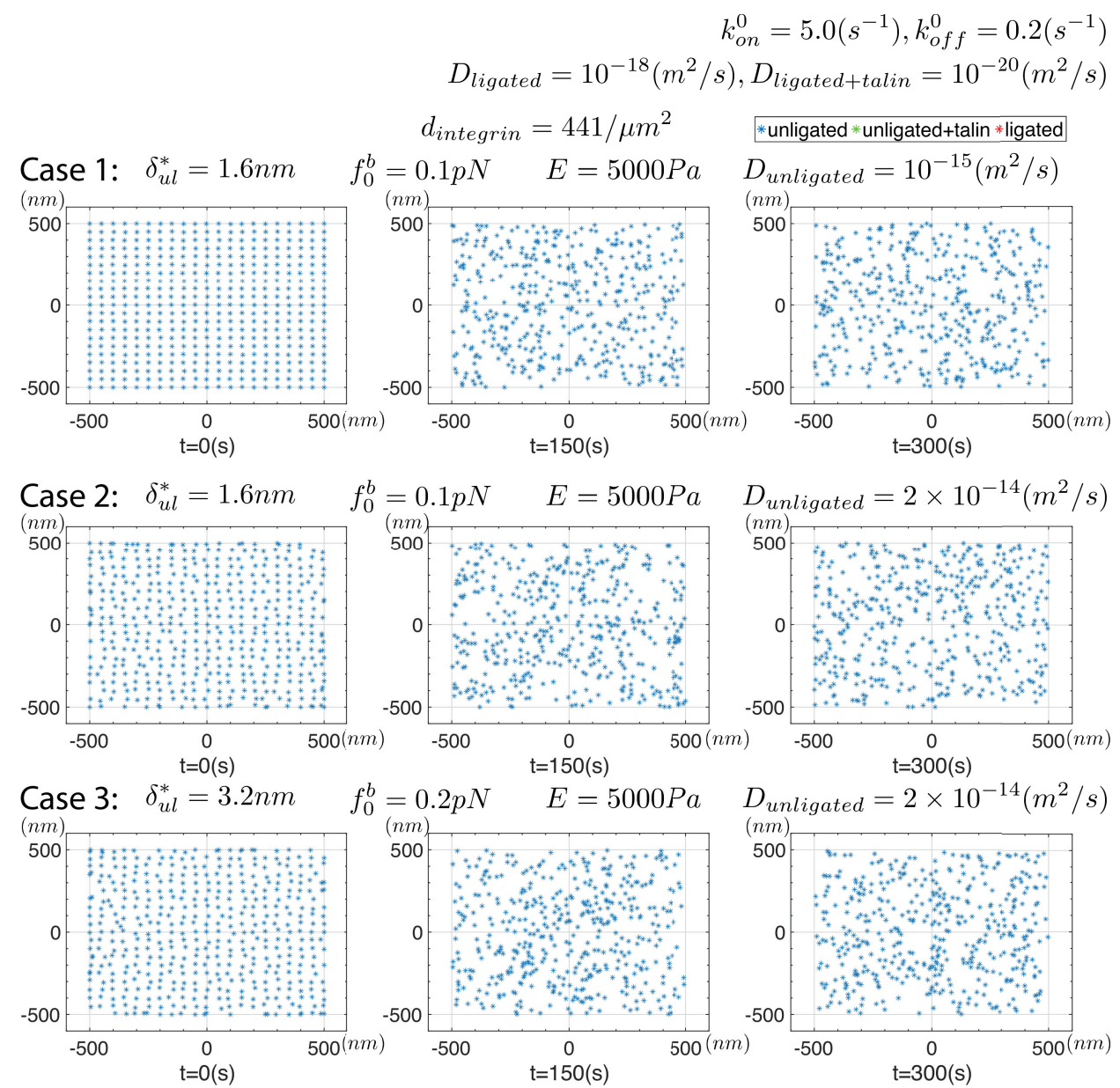

Figure 5. Results for a series of simulations where $\delta_{u l}^{\star}=1.6 \mathrm{~nm}$ and $3.2 \mathrm{~nm}$ for unligated integrins and in which ligation was precluded. Two levels of integrin mobility were used with $D=10^{-15} \mathrm{~m}^{2} \mathrm{~s}^{-1}$ and $D=2 \times 10^{-14} \mathrm{~m}^{2} \mathrm{~s}^{-1}$.

The underlying reason for this trend lies simply in the relative balance of random "thermal forces" vs. the relatively weak attractive forces due to type of interaction. Close examination of the integrin distributions at longer times, however, reveals occasional loose, but transient, aggregations. These aggregates may be accentuated with increased $\delta_{\ell}^{\star}$, but as noted this would seem to suggest the need for additional experimental justification to motivate and justify even larger values of $\delta_{u l}^{\star}$; we recall from Equation (8) that, if $f_{0}^{b}=0 \mathrm{pN}$, $\delta_{u l}^{\star}=f_{0}^{b} / k \approx 1.6 \mathrm{~nm}$ and so on with increasing values of $f_{0}^{b}$. For further perspective on this we again refer to the most interesting simulation studies of Reynwar et al. [58] who simulated large lipid membrane distortions caused by binding of protein capsids of various size and curvature.

Figure 6 summarizes results from a series of simulations in which we assume that unligated integrins do not create an elastic field, i.e., where $\delta_{\mu l}^{\star}=0$; this means unligated integrins do not interact with the elastic fields of ligated integrins, i.e., they simply undergo random diffusion wherein they may ligate with enhanced rate if near a ligated integrin or cluster. All parameters are listed in the figure. Since the diffusion coefficient of ligated integrins is some 3 orders of magnitude less than that of active but un-ligated integrins, we expect that the only effect promoting clustering is the enhanced ligation rate, i.e., $k_{\text {on }}$ of Equation (18). In all these simulations the initial distribution of integrins was taken as uniform with a density of $d_{\text {int }}=441 \mu \mathrm{m}^{2}$.

Of the key parameters involved, we observe the influences of $\delta_{\ell}^{\star}, E$, and $D$. For example, for $E=5000 \mathrm{~Pa}$ we observe that clusters do indeed form over times of $\mathcal{O}(1-2 \mathrm{~min})$ and tend to remain stable as long as $\delta^{\star}<30 \mathrm{~nm}$; for $\delta^{\star}>30 \mathrm{~nm}$ stable clusters do not 
survive. This was the case with $D=10^{-15} \mathrm{~m}^{2} \mathrm{~s}^{-1}$. Yet, and again with $\delta_{\ell}^{\star}=40 \mathrm{~nm}$ and $D=10^{-15} \mathrm{~m}^{2} \mathrm{~s}^{-1}$, but with $E=1500 \mathrm{~Pa}$, we once again find observe stable clustering. We note, however, that the clusters tend to be rather small and contain but a few integrins; typically we observe on order of 5-7 integrins in all of the clusters shown in Figure 6 with the initial density of $d_{\text {int }}=441 \mu \mathrm{m}^{2}$. Hence clusters do form on substrates of all rigidity as Changede and Sheetz report [32,33], at least within the range of $E, D$, and $\delta_{\ell}^{\star}$ we use here; clusters do tend, however, to be less stable on more rigid substrates. Changede et al. [32] noted that nascent clusters tended to be less persistent on stiff, viz. glass, substrates than on less rigid, viz. supported lipid bilayer (SLB), substrates, an observation consistent with the observations of Choi et al. [34]. Our observations of the effect of stiffness may provide the beginnings of an understanding of how that transient process unfolds. Changede et al. [32] suggest, though, that "... the turnover of the adhesions was a second step that was stimulated by extracellular traction force", a step we do yet include in our simulations. Choi et al. [34] discuss that nascent adhesion turnover is "... independent of myosin II", and hence this process will require further study. The clusters so far discussed in our simulations do tend to be smaller than they report and that requires further inquiry as we look to next.

Figure 7 shows results for a compatible set of cases as Figure 6 where a pre-force is assumed as described above. As it happens, the differences are not great except for the observation that the clusters are sightly larger and tend to contain slightly more integrins on order of 6-8. One observation relevant to reported observations, is that there are now more unligated integrins found within the clusters; this is in addition to the also consistent increased size and cluster integrin density. Although the pre-forces, $f_{0}^{b}$, are of quite modest magnitude we find they do have noticeable effects such as increased cluster size and integrin number density within clusters. Since the displacement fields of an unligated integrin does contribute to the net required displacement beneath a ligated integrin, we expect their proximity to ligated integrins reduces the internal force and helps stabilize the ligation bond; recall that bond is considered a "slip-bond", not a "catch-bond". This effects is, however, quite modest and at the rather modest level of the internal forces of $\mathcal{O}(\sim 1 \mathrm{pN})$, or less, the bond type difference is itself modest. We note in passing, though, that the difference in bond type would be important when the actin-myosin cytoskeleton forces are applied as in mature FAs [77,79]. Regarding stable clusters, here again we observe that when $\delta_{\ell}^{\star}>30 \mathrm{~nm}$ stable clusters are not observed. A quite different picture is obtained, however, if the the integrin mobility is somewhat larger; we turn attention to the effect of mobility next in Figure 8.

In Figure 8 we explore the effects of a larger integrin mobility and, as it happens, increased integrin mobility appears to have substantial effects with respect to both the time scales for initial clustering and longer time clustering. With $D=2 \times 10^{-14} \mathrm{~m}^{2} \mathrm{~s}^{-1}$, for instance, we note that aggregation of integrins appear only after times $\sim 10 \mathrm{~s}$ as opposed to $\sim 300 \mathrm{~s}$ when $D=10^{-15} \mathrm{~m}^{2} \mathrm{~s}^{-1}$. It is important to recall that this acceleration is not merely the effect of diffusion per se, but of an increase in viscous mobility, $1 / \zeta=D / k T$. Cluster size is also increased, with the number of clusters decreased and the number of integrins found within clusters increased.

Cases \#2 and \#3 of Figure 8 are particularly interesting in that they display a reduced number of clusters whose sizes are significantly larger than appears in the simulations shown above. This effect with enhanced integrin mobility has its roots in one of the basic features of our model. Essentially, an explanation would go something like this. Once initial integrins ligate, they more quickly attract unligated integrins and also provide significantly higher probability of ligation in their vicinity, that is in the vicinity of a de novo nascent cluster. Hence, the de novo cluster develops rapidly. Its stability is assured due to the cooperation among displacement fields of the integrins such that only quite modest internal forces develop in each integrin within the cluster, i.e., $k_{\text {off }}$ is maintained at a low level. When $\delta_{\ell}^{\star}$ is high enough, e.g., when $\delta_{\ell}^{\star}=80 \mathrm{~nm}$ in this case, this is no longer the case. 
Taken together, the above results demonstrate that the proposed mechanisms do naturally lead to integrin clustering with time scales consistent with reported observations. However, the details such as cluster size, and the number of integrins found within each typical cluster, depend on factors such as internal force levels within integrins, integrin mobility, and to a lesser extent system stiffness per se. These insights certainly suggest that further quantitative detail is required regarding integrin mobility as well as an assessment of system stiffness, e.g., what is taken as $E$ herein. System stiffness, moreover, needs to be viewed in a more holistic manner, e.g., to include at least some assessment of the potential contributions of the cell's glycocalyx [79,82]. To gain additional insight we refer to Figure 9 that shows cluster results for systems of nominally higher integrin density, viz. $d_{\text {int }}=841 \mu \mathrm{m}^{-2}$.

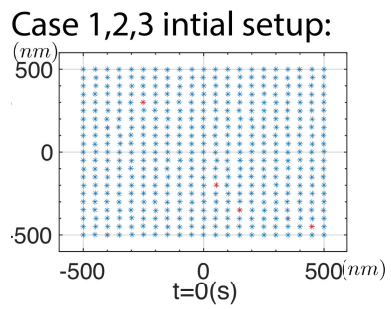

$$
\begin{array}{r}
k_{\text {on }}^{0}=5.0\left(\mathrm{~s}^{-1}\right), k_{\text {off }}^{0}=0.2\left(\mathrm{~s}^{-1}\right) \\
D_{\text {ligated }}=10^{-18}\left(\mathrm{~m}^{2} / \mathrm{s}\right), D_{\text {ligated }+ \text { talin }}=10^{-20}\left(\mathrm{~m}^{2} / \mathrm{s}\right) \\
d_{\text {integrin }}=441 / \mu \mathrm{m}^{2} \quad \text { *unligated *unligated+talin*ligated }
\end{array}
$$

Case 1: $\delta_{l}^{*}=10 \mathrm{~nm}$ $f_{0}^{b} \underset{(n m)}{=0.0 p N} \quad E=5000 P a$
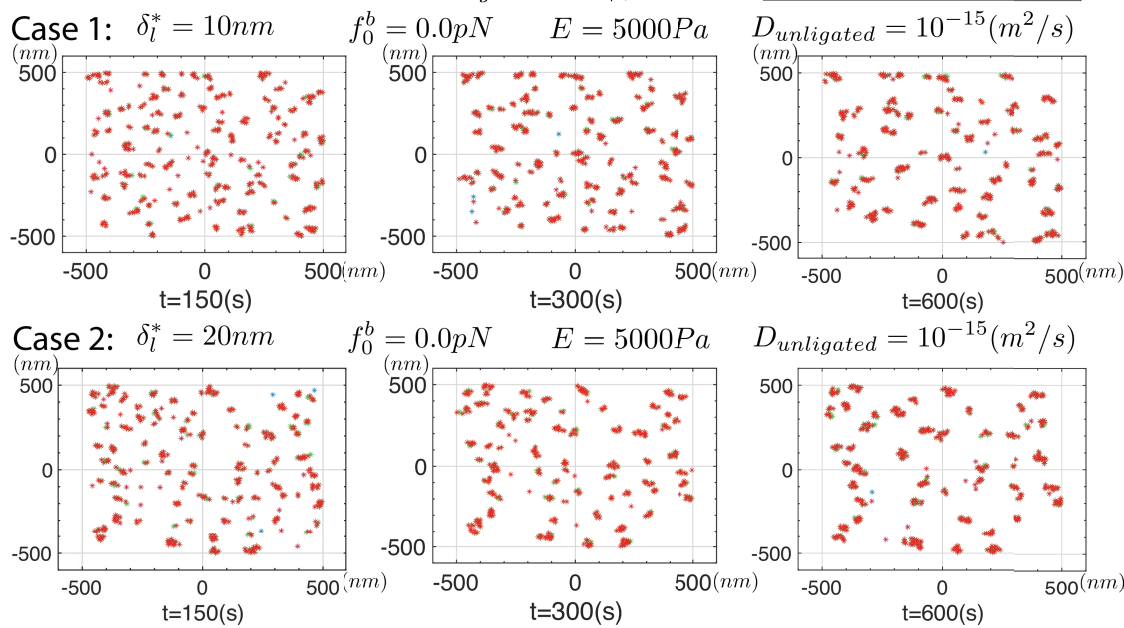

$f_{0}^{b}=0.0 p N \quad E=5000 P a$

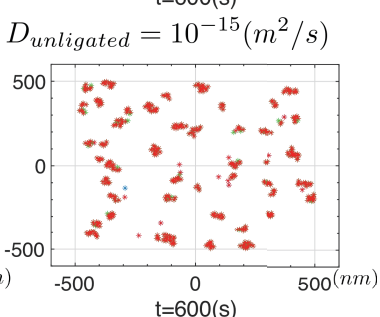

Case 3: $\delta_{l}^{*}=40 \mathrm{~nm}$

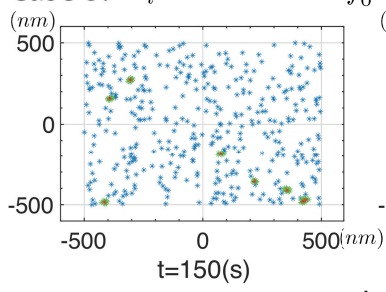

$$
f_{0}^{b}=0.0 p N \quad E=5000 P a
$$

$D_{\text {unligated }}=10^{-15}\left(\mathrm{~m}^{2} / \mathrm{s}\right)$
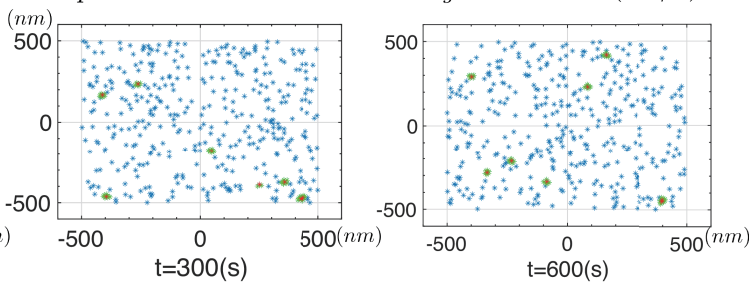

Case 4: $\delta_{l}^{*}=40 \mathrm{~nm}$

$$
f_{0}^{b}=0.0 p N
$$

$E=1500 P a$

$$
D_{\text {unligated }}=10^{-15}\left(\mathrm{~m}^{2} / \mathrm{s}\right)
$$
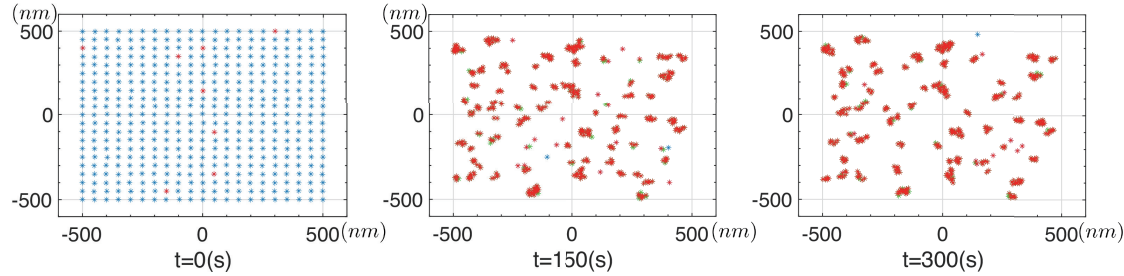

Figure 6. Results for a series of simulations where $\delta_{u l}=0$ for unligated integrins; the frames are snapshots of a continuous simulation for greater that $600 \mathrm{~s}$. All parameters are listed for the 4 cases considered. The initial integrin distribution is is shown in the upper left. 


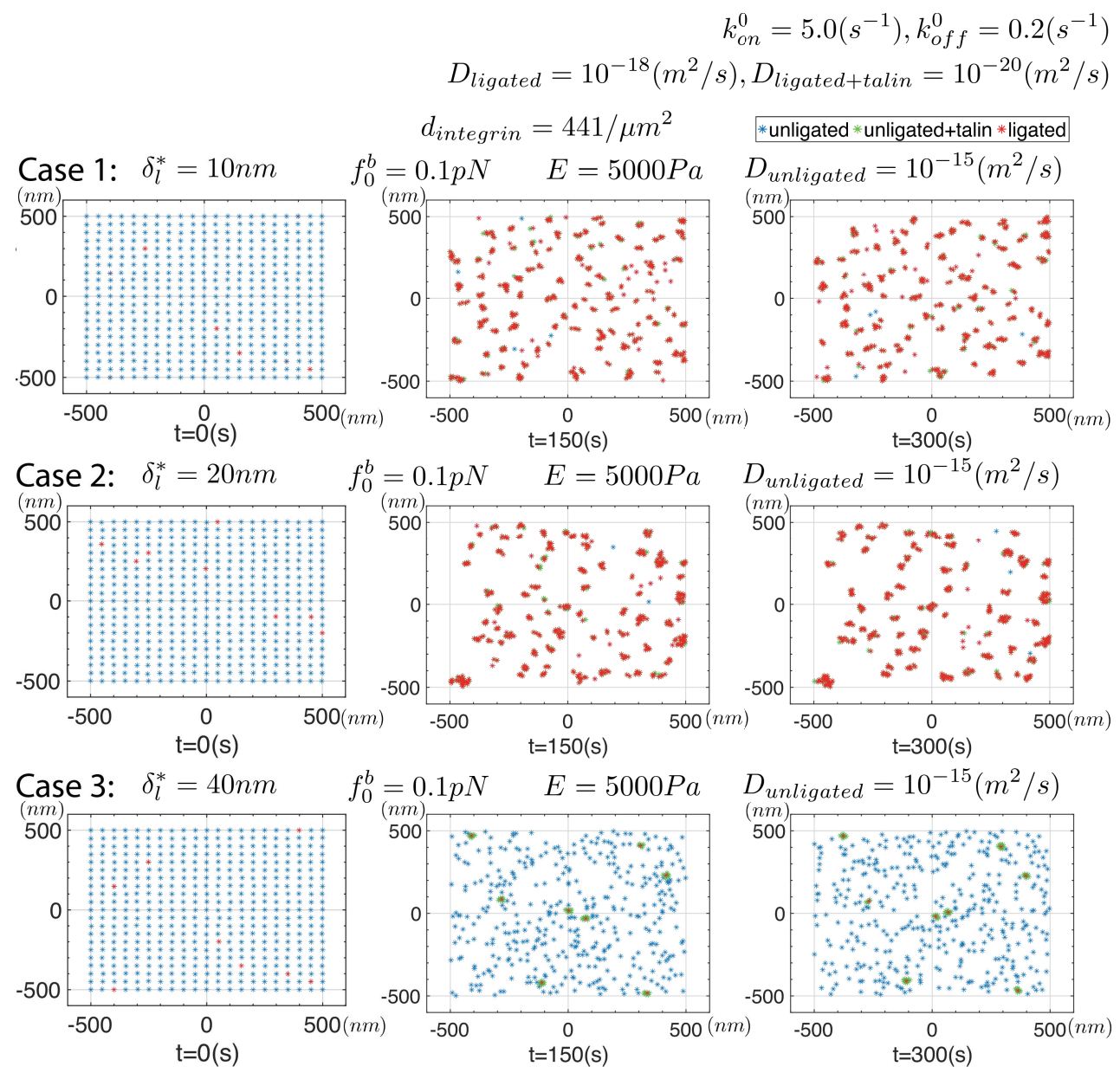

Figure 7. Snapshots taken from simulations in which a pre-force, $f_{0}^{b}$, is imposed on unligated integrins. All parameters are listed for each of the 3 cases considered. The initial integrin distribution is as shown in Figure 6.

Figure 9 shows results for two cases, both with $d_{\text {int }}=841 \mu \mathrm{m}^{-2}, \delta_{\ell}^{\star}=20 \mathrm{~nm}$, and $E=5000 \mathrm{~Pa}$, but with $D=10^{-15} \mathrm{~m}^{2} \mathrm{~s}^{-1}$ and $D=2 \times 10^{-14} \mathrm{~m}^{2} \mathrm{~s}^{-1}$. The most obvious, and perhaps expected, result is a general increase in the size and expected number density of integrins per cluster; cluster size is of $\mathcal{O}(100 \mathrm{~nm})$, most particulary with $D=2 \times 10^{-14} \mathrm{~m}^{2} \mathrm{~s}^{-1}$, i.e., higher integrin mobility. The number density of integrins is in the range of 30-50 integrins per cluster. We note that to approach such cluster sizes with lower $d_{\text {int }}$, larger $\delta_{\ell}^{\star}$ was required as in cases \#1 and \#2 of Figure 8 showed. The general trends in cluster formation were not altered with increases in $d_{\text {int }}$ but clusters appeared at earlier times which, of course, would be expected. A most notable effects of $\delta_{\ell}^{\star}$ was to increase the eventual stable cluster size, which formed after $\sim 100 \mathrm{~s}$, and that appears in the range $d_{\mathrm{cl}}=100 \pm 20 \mathrm{~nm}$, as determined from range of 20 such simulations.

\subsubsection{Cluster-Cluster Interaction}

As a final example we address the question of cluster-cluster interactions; for this we refer to Figure 10. Here we assume that ligated integrins may possess higher mobility, this motivated by Changede and Sheetz's [32] report that clusters on supported lipid bilayers (SLBs) tend to aggregate. How ligated integrins on an ECM diffuse, however, is unclear yet on the SBLs they used ligands were reported to be mobile. The effect of increasing $D_{\ell}$, and in fact the effect of allowing mobility of ligated integrins at all, is sigificant indeed. In Case \#1 of Figure 10, with $\delta_{\ell}^{\star}=30 \mathrm{~nm}$, we observe very early clusters that take on sizes $\sim 100-200 \mathrm{~nm}$ and rapidly recruit unligated integrins that ligate with enhanced rate. We do recall however that, since the internal forces within "would be" ligated integrins are 
modestly reduced, the effect of large clusters is to increase $k_{\text {on }}$ toward the value $k_{\mathrm{on}}^{0}$ in Equation (18). The clusters are quite dynamic in that ligated integrins tend to unligate and re-ligate, unless they should diffuse away unligated; in this particular simulation if an integrin unligates we reset $D_{u l}=2 \times 10^{-14} \mathrm{~m}^{2} \mathrm{~s}^{-1}$ and indeed we observe such occasional motions as described just below. Rossier et al's. [93] findings on integrin mobility might suggest a refinement of this by noting that if an integrin unligates while within a cluster's interior it may find itself "corralled" and hence less mobile; such refinements are readily accommodated, yet were not here.

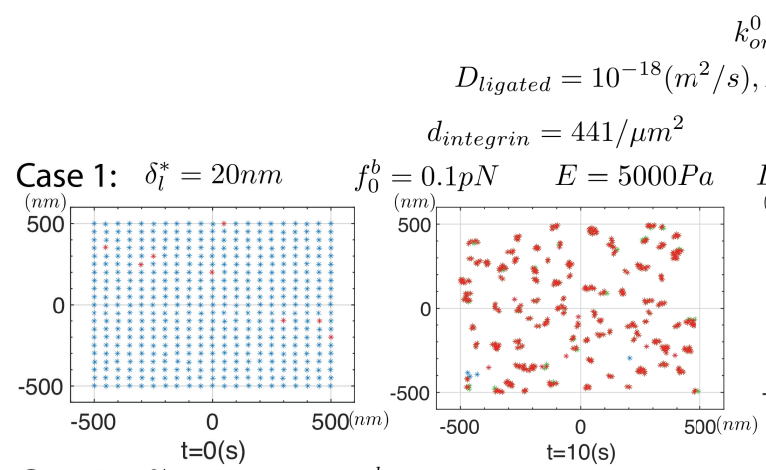

$$
\begin{array}{r}
k_{\text {on }}^{0}=5.0\left(\mathrm{~s}^{-1}\right), k_{\text {off }}^{0}=0.2\left(\mathrm{~s}^{-1}\right) \\
D_{\text {ligated }}=10^{-18}\left(\mathrm{~m}^{2} / \mathrm{s}\right), D_{\text {ligated+talin }}=10^{-20}\left(\mathrm{~m}^{2} / \mathrm{s}\right)
\end{array}
$$$$
d_{\text {integrin }}=441 / \mu m^{2}
$$

*unligated $*$ unligated+talin *ligated

$f_{0}^{b}=0.1 p N \quad \stackrel{\mathrm{t}=10(\mathrm{~s})}{E}=5000 P a$

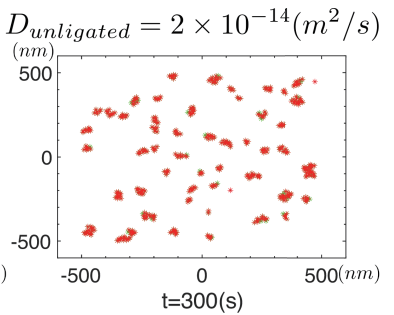

Case 2: $\quad \delta_{l}^{*}=30 \mathrm{~nm}$
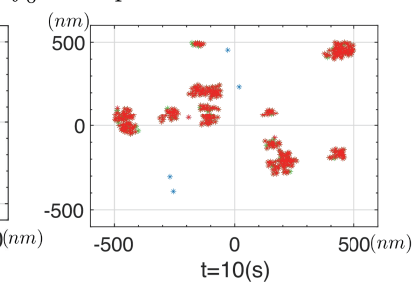

$D_{\text {unligated }}=2 \times 10^{-14}\left(\mathrm{~m}^{2} / \mathrm{s}\right)$
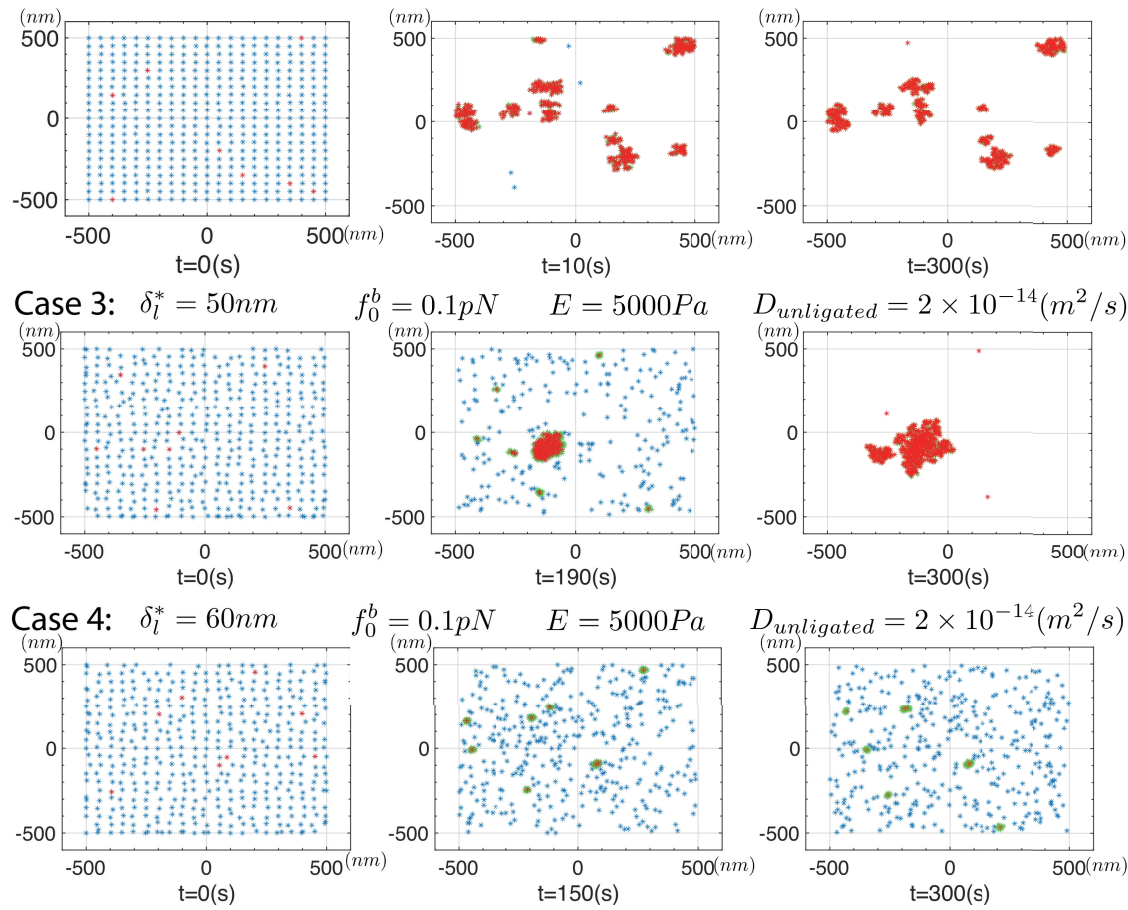

Figure 8. Snapshots of simulations for 4 cases in which the integrin mobility is increased to $D=2 \times 10^{-14} \mathrm{~m}^{2} \mathrm{~s}^{-1}$. Note the significant effect increased mobility has on increasing cluster size while maintaining cluster stability. 


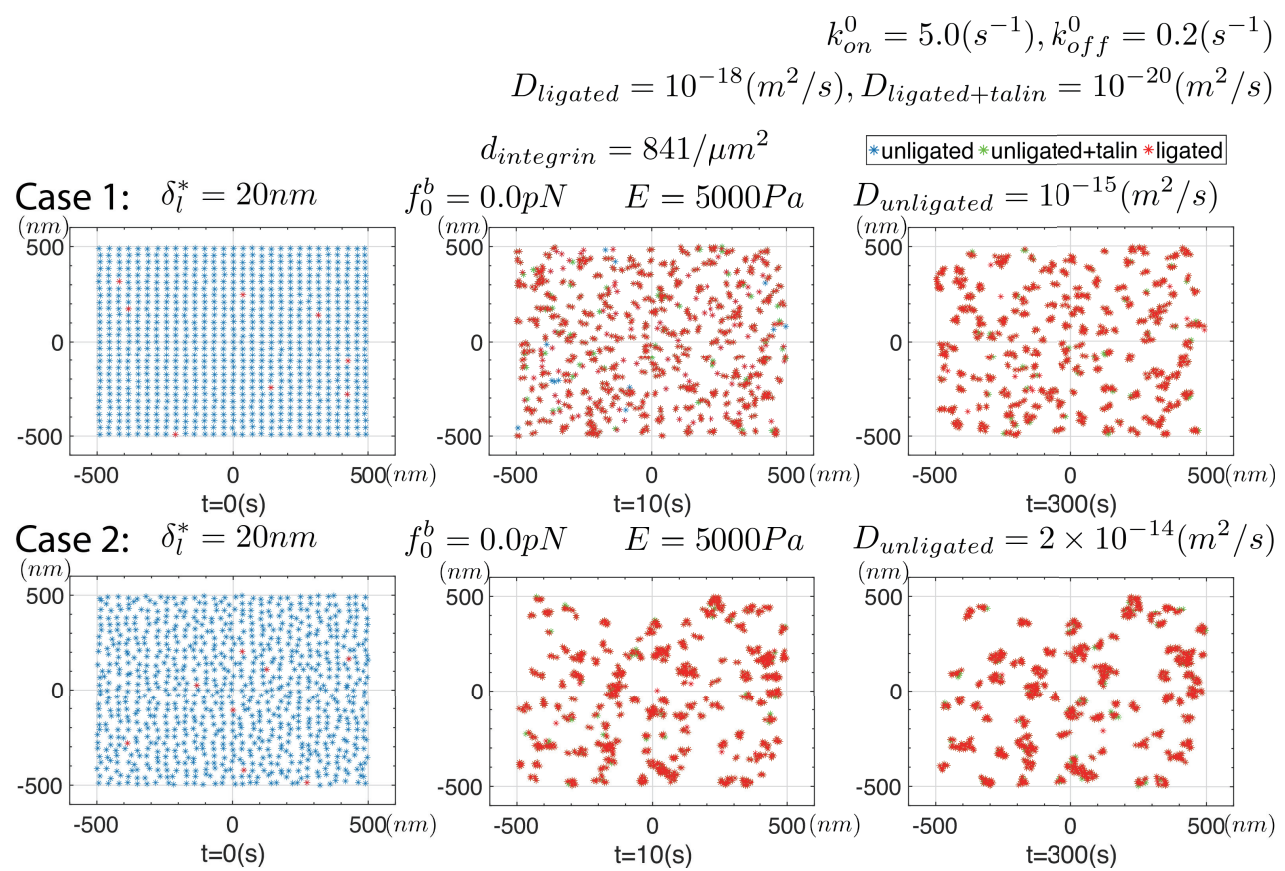

Figure 9. Simulations involving higher initial integrin density and modest integrin mobility (Case \#1) and increased mobility (Case \#2). Note the increase in cluster size and average integrin numbers within clusters with enhance mobility.

The dynamics of the clusters is such that they tend to drift toward each other as noted by Changede and Sheetz [32], at least for those clusters whose integrins are bound by talin rod (TR). This drifting motion, however, occurs not by a discrete motion of clusters per se. Motion occurs by the slow ligation at those regions on the periphery of clusters juxtaposing nearby clusters. The simple scenario of this simulation evolves into a single cluster.

We then reduced $D_{\ell}=10^{-17} \mathrm{~m}^{2} \mathrm{~s}^{-1}$ and observed a similar yet temporally different evolution of clusters that first formed and then drifted toward each other; this is shown in Figure 10 as Case \#2.

Note that after $300 \mathrm{~s}$ the clusters have "grown" by merging to sizes of $\mathcal{O}(200-300 \mathrm{~nm})$. These clusters drift, typically toward each other, as described below.

To obtain a more detailed look at such cluster dynamics we performed additional simulations with the same parameters of Case \#2 of Figure 10 and extracted snapshots at time intervals of $\delta t=0.1 \mathrm{~s}$; an example is shown with Case \# 2 of Figure 10. This cluster, that contains at various moments within the $3 \delta t$ time interval shown approximately 35-37 integrins, is drifting dextra (toward the right) in this scenario. The mechanism of motion can be seen by the movement of integrin " $\mathrm{i}$ ", sinister (to the left) to the cluster where it becomes bound to the cluster via talin (see figure legends); integrin " $\mathrm{i}$ " is expected to then ligate, at least with a higher probability. In addition, we observe at least two examples of transitions in state of integrins " $\mathrm{j}$ " and " $\mathrm{k}$ " between the time $3 \delta t$ between $t=21.7 \mathrm{~s}$ and $t=21.8 \mathrm{~s}$. Integrin " $\mathrm{j}$ " has transitioned from being bound to a ligated integrin via talin to a ligated integrin on the left edge of the cluster to being unligated (i.e., free); this is part of the cluster's drifting dextra. In the meantime integrin " $\mathrm{k}$ ", that is within the cluster, transitions from being ligated and unligated. It is indeed possible to turnover large fractions of ligated integrins within a cluster in this manner. Such visualizations also make it clear how further refinements in specifying character or parameters changes of integrins may be readily accommodated.

With regard to cluster drifting, however, we note that Changede and Sheetz [32] have reported that in cells expressing either talin head domain (THD) or the talin rod (TR) the motility is different; mechanisms for such differences remain to be explained. What also remains to be described is how nascent clusters de-stabilize, disassemble, and disappear. 

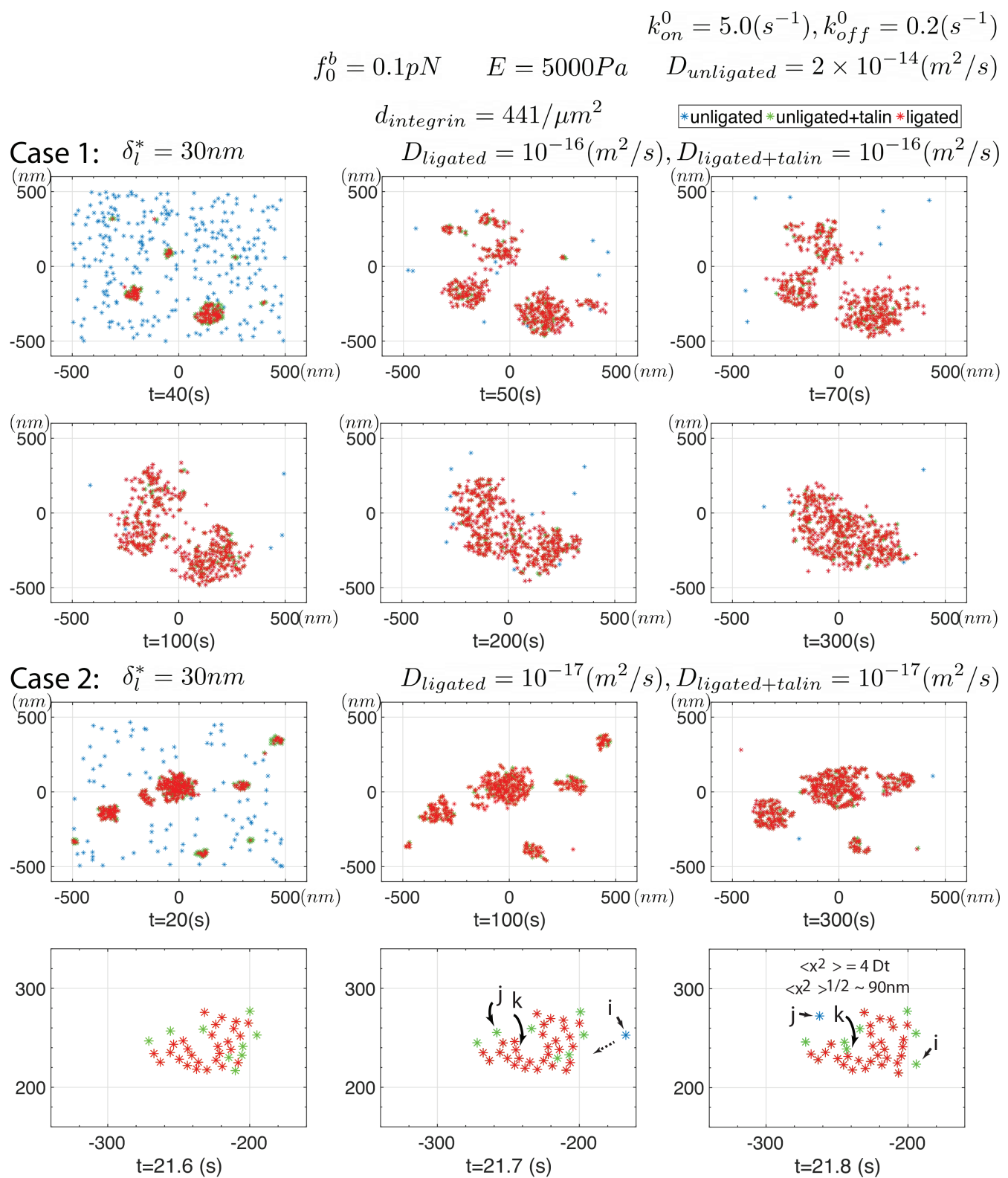

Figure 10. Simulation of nascent cluster interaction visualized by prescribing an enhance mobility to ligated integrins. All parameters are listed. Clusters tend to attack due similar force fields as described for individual ligated and activated integrins. Case \#2 details cluster drifting and the dynamics of cluster motion and integrin turnover within a cluster.

\section{Discussion}

We have presented a framework, and a specific model, for the formation of nascent adhesions based on reported phenomenology, as cited, and a rather simple physical description of integrin bonding, via ligation, to substrates. Substrates, in our view, do not necessarily mean stiff media such as extracellular matrices or organic slides, but may indeed be soft matter such as supported lipid bilayers (SLBs) as described and used by Changede and Sheetz [32,33]; the cell's membrane itself has finite bending stiffness. The idea behind our approach is also to be found in in the molecular dynamics simulation studies of, for example, Reynar et al. [58,59] who demonstrated that capsid-like protein "particles", bound to lipid membranes, cause local membrane deformations that drive clustering, more intense deformations, and that may even lead to vesicle formation. The fundamental driving forces here are similar, namely the reduction in total free energy upon clustering of those entities, viz. protein capsids in Reynar et al. [58,59], and integrins herein, that are 
the so-called sources of deformation. We note that the simulations of Reynar et al. [58,59] of interacting proteins were preformed on free membranes that tended to take on large curvatures; in fact our mechanisms and formalisms is quite applicable to such curvatures. The cell-substrate interactions modeled in this study, however, occur on interfaces of quite modest curvature as affected by the protein distortions we model. We add, however, that unlike the clustering of bound capsids discussed by Reynar et al. $[58,59]$ the dominant clustering effect here is due to integrin ligation and not the binding of the THD or kindlins.

Our model also specifically calls attention to the role of the cell's glycocalyx, a feature that has been discussed by Paszek et al. [80,82], and more recently by Kanyo et al. [44] with regard to cancer cells; this important, and ubiquitous, cell component is, unfortunately, to often neglected in such studies of cell adhesion. Hence, the discussion of Paszek et al. [80,82] and most particularly of Kanyo et al. [44] should receive more attention and has been, e.g., in the considerations of Asaro et al. [79] in describing the formation of traction force in FAs.

In particular, Kanyo et al. [44] observed and analyzed, via a kinetic model, the strength and rate of formation of integrin-RGD ligand complexes as they enzymatically digested specific glycocalyx components of HeLa cancer cells. Among the results they reported was that at a sufficient concentration of enzyme treatment reduced integrin-ligand binding was observed. At the lower enzyme concentrations they used, however, integrin-ligand binding was increased and then significantly decreased with higher concentration. Moreover, their kinetic analysis showed that the recruitment rate of integrins into the adhesion decreased with increased enzyme concentration. The integrin-ligand dissociation rate was essentially unaffected by enzyme concentration; interestingly, $k_{\text {off }}$ reported by Kanyo et al. [44], i.e., the $k_{2}$ in their Equation (2) and reported in their Figure 8b, was nearly identical to our $k_{\text {off }}=0.2 \mathrm{~s}^{-1}$ used in most of our simulations. That the integrin recruitment rate was reduced by enzymatic digestion is in itself consistent with the fact that our interaction forces that drive recruitment, and thereby clustering, would be reduced by removing parts of the glycocalyx. The insensitivity of the integrin-ligand dissociation rate to enzyme concentration may well be explained by the bond force range that develops via a catch-bond analysis [77]. This remains an interesting observation that should be analyzed further when additional data becomes available, although Kanyo et al. [44] present a view that that kosmotropic salting-out of integrins and glycocalyx into two phases would diminish, or even preclude, the glycocalyx from affecting the integrin-ligand bond strength, hence the lack of sensitivity of $k_{\text {off }}$ to enzyme concentration. They thereby suggest such salting-out may be a mechanism for integrin clustering. In fact, since our interaction forces basically involve distortions of the membrane-glycocalyx-ECM system, the two mechanisms may be viewed in parallel; that is, the role of the glycocalyx per se may be of greater or lesser importance in various cases and the phase separation of salting-out may be viewed in parallel with our mechanical interactions. Still another way of saying this is: if the glycocalyx were reduced, or even, nearly removed, from Figure $3 c, d$ the interactions we analyze would persist although at an altered intensity; these mechanical interactions may be weakened which would help explain a reduced integrin recruitment rate with glycocalyx digestion. Indeed, thermodynamic approaches to salting out have been pursued [94,95] and in our case we may express parallelism of mechanisms in terms of integrin chemical potential with a conceptual model approach that might be phrased something like this: let the chemical potential of integrins be written, with $k$ Boltzman's constant and $T$ absolute temperature, as

$$
\mu_{i}=\mu^{0}+k T \ln \gamma_{m} \gamma_{s} c_{i},
$$

where the interactions we describe herein and the reduction in solubility due to salting-out would be contained in the activity coefficients $\gamma_{m}\left(\mathbf{x} ; \mathbf{x}_{j}, \mathbf{f}\right)$ and $\gamma_{s}(\mathbf{x}, \mathbf{f})$, respectively and $c_{i}(\mathbf{x})$ is the integrin concentration. The energies associated with these effects would be associated with their contributions to $\mu_{i}$, viz. $k T \ln \gamma_{m}$ and $k T \ln \gamma_{s}$. Hence the energies associated with mechanical and salting-out solubility dependence would be position dependent, where $\mathbf{x}$ is an integrin position vector, $\mathbf{x}_{j}$ is a set of position vectors for interacting integrins, and $\mathbf{f}$ is 
a vector of parameters describing the state of the glycocalyx. Whether such an approach or some other, future study is warranted to explore such combined effects as additional observations of the type reported on by Kanyo et al. [44] are pursued. We do add, however, that our results demonstrate the importance of integrin mobility and we have suggested that this be documented for any particular case under study.

The framework of our model allows, by design, wide flexibility with regard to including additional features such as, inter alia: (1) patterned ligand distributions; (2) variable integrin mobility; (3) kinetic descriptions of ligation and unligating; and (4) the influence of "applied forces" as may arise due to actin-myosin contractility; by simply extending the model to include actin-myosin forces, the evolution of mature may be explored. Of course, this will entail a holistic treatment of the stochastic nature of the adhesome's force train as considered by Asaro et al. [79]; in that analysis they showed how mechanosensitivity occurred all along the adhesome and hence attempts to attribute such to a simple anonymous set of "clutch bonds" is inappropriate and unrealistic.

Our analysis has revealed several noteworthy features of the clustering process, yet there are many unknowns, as expected. These findings include, inter alia:

1. We have demonstrated that nascent clusters should form on substrates of all rigidities, a claim made in the title of Changede and Sheetz [32,33]. This basis for their finding becomes clear upon the realization that a driving force for clustering stems from the energy reductions that follow clustering as illustrated by attractive pairwise force between integrins given in, e.g., Equation (7). As noted earlier, this force scales directly with terms such as $f_{\alpha}^{\star} \partial \delta / \partial \xi$ where $f_{\alpha}^{\star}$ and $\partial \delta / \partial \xi$, respectively, scale as $E$ and $1 / E, E$ being the system rigidity (stiffness). Hence, the this force does not depend strongly on system rigidity; the internal force within an integrin, however, does depend on system rigidity and that will affect ligation bond survival time. Of course, this basis may also be appreciated by the simulations of Reynar et al. [58,59] noted above; in those cases there was no substrate, but only the free energy of the deformed membrane.

2. Our simulations reveal important quantitative and qualitative effects of integrin mobility, on clustering as illustrated in Figure 10, and by comparing Figure 10 with Figure 9, as examples. First, we observe that clusters tend to be larger when the mobility of unligated integrins is increased; in the specific case studies clusters were in the size range $\sim 100 \mathrm{~nm}$ (in Figure 9) and with a factor of 5 increase in $D_{\text {unligated }}$ were more in the range of $\sim 200 \mathrm{~nm}$ (in Figure 10) in diameter. Moreover, if ligated integrins were ascribed a somewhat increased mobility, clusters were observed to "drift" so that they aggregated. To visualize why this may happen, we noted that clusters that stand apart by some distance from each other appear as "large point forces" and hence attract with a force similar in kind to that described by Equation (7) for single integrin pairs; this is the thermodynamic force driving the drifting motion. The actual mechanism for this drifting involves integrin unligation and ligation at the juxtaposed peripheries of merging clusters as illustrated in the simulation frames shown for Case \#2 of Figure 10. But the question arises: what accounts for this enhanced mobility of ligated integrins? In the cases studied by Changede and Sheetz [32], involving cells on supported bilipid layers (SBLs), they reported that the ligands on SBLs were mobile. For cells adhered to an ECM or an organic substrate this would remain an open question. Nonetheless, if clusters are observed to aggregate, this offers a potential mechanism. Clearly, this sort of observation, among others, suggests that integrin mobility is an important determinant for deciphering cluster dynamics and hence experimental studies of clustering will be deficient without such information.

3. On the question of integrin mobility we note the study of Rossier et al. [93] as a noteworthy example. Their study was particularly concerned with understanding the role of, in particular $\beta_{1}$ and $\beta_{3}$ containing, integrins dynamics on FAs in fibroblasts on fibronectin substrates. We have used these studies to motivate our variations in diffusion coefficient as explained in our case studies above. Accordingly, we "immobilize" integrins upon ligation where we have assumed that the integrins bind 
talin, and possibly kindlins as well; this is done by assigning a nearly vanishingly small value of $D_{\text {ligated }} \sim 10^{-18} \mathrm{~m}^{2} \mathrm{~s}^{-1}$. Rossier et al. [93] defined integrin confinement within FAs in terms of a radius, $r_{\text {conf }}$, and with that specified diffusion coefficients accordingly. This sort of detail may be incorporated into a model such as ours for further refinement.

4. Finally we add that our model helps explain the patterns of integrin clustering observed in the experiments we have cited, e.g., [32-34], that are some of the most comprehensive conducted to date. In particular, we find that the numbers of integrins that appear in clusters appears to lie in the range of 30-50 which is again typical to what is observed experimentally [32,33]; this in itself is a noteworthy and not obvious trend. However we also note that depending on factors such as the initial density of integrins and the magnitude of diffusion coefficients numbers outside this range are indeed possible. For this reason we have made special note that future studies of nascent clustering should document the mobility of integrins as well as their expressed numbers.

Further progress may be made by combining the sort of detailed observations of nascent cluster formation as reported by Changede and Sheetz $[32,33]$ with a more holistic study of integrin mobility as performed by Rossier et al. [93]; this would provide a better documented case study to explore the veracity of models of the type we have presented herein. Cellular details pertaining to cell glycocalyx as well as integrin activation kinetics for the identified adhesion integrin-ligand system would, of course, be invaluable. Without such a quantitative basis, models can only render trends and potentialities, not true forecasts or explanations. In fact, the immediate value of models such as presented here is to better define what is needed and why it is needed.

Finally, we suggest that a particularly important feature (mystery?) of nascent cluster adhesions is their disassembly, i.e., if they fail to mature into FAs. This process may lie at the heart of our eventual understanding of cell adhesion, mechanosensitivity, and mechanotransduction. Once the disassembly process has been better understood in a mechanistic sense, other critical details such as the stochastic, force rate, and time dependent traction forces that develop due to cytoskeleton contractility may also be better understood in a modeling sense, e.g., $[72,73,79,81]$. The same is true for vital processes such as cell migration which involves both adhesion formation and disassembly.

Author Contributions: R.J.A. and K.L. both contributed to, and performed the research. The manuscript was written by R.J.A. and K.L. All authors have read and agreed to the published version of the manuscript.

Funding: This research received no external funding.

Data Availability Statement: Data is available upon request from the corresponding author.

Conflicts of Interest: The authors declare no conflict of interest.

\section{References}

1. Janmey, P.A.; Winer, J.P.; Murray, M.E.; Wen, Q. The hard life of soft cells. Cell Motil. Cytoskelet. 2009, 66, 597-605. [CrossRef]

2. Engler, A.J.; Sen, S.; Sweeney, H.L.; Discher, D.E. Matrix elasticity directs stem cell linkage specification. Cell 2006, 126, 677-689. [CrossRef]

3. Lo, C.M.; Wang, H.B.; Dembro, M.; Wang, Y.L. Cell movement is guided by the rigidity of the substrate. Biophys. J. 2000, 79, 144-152. [CrossRef]

4. Yeung, T.; Georges, P.C.; Flanagan, L.A.; Marg, B.; Ortiz, M.; Funaki, M.; Zahir, N.; Ming, W.; Weaver, V.; Janney, P.A. Effects of substrate stiffness on cell morphology, cytoskeleton structure, and adhesion. Cell Motil. Cytoskelet. 2005, 60, 24-34. [CrossRef]

5. Thomas, W.E.; Discher, D.E.; Shastri, V.P. Mechanical regulation of cells by materials and tissues. MRS Bull. 2010, 35, 578-583. [CrossRef]

6. $\quad$ Engler, A.J.; Carag-Krieger, C.; Johnson, C.P.; Raab, M.; Tang, H.Y.; Speicher, D.W.; Sanger, J.W.; Sanger, J.M.; Discher, D.E. Embryonic cardiomyocytes beat best on a matrix with heart-like elasticity: Scar-like rgiidity inhibits beating. J. Cell Sci. 2008, 121, 3794-3802. [CrossRef] [PubMed]

7. Lipski, A.M.; Pino, C.J.; Haseiton, F.R.; Chen, I.W.; Shastri, V.P. The effect of silica nanoscale-modified surfaces on cell morphology, cytoskeletal organization and function. Biomaterials 2008, 29, 3836-3846. [CrossRef] [PubMed] 
8. Lord, M.S.; Foss, M.; Besenbacher, F. Influence of nanoscale surface topography on protein adsorption and cellular response. Nano Today 2010, 5, 66-78. [CrossRef]

9. Maheshwari, G.; Brown, G.; Lauffenburger, D.A.; Wells, A.; Griffith, L.G. Cell adhesion and motility depend on nanoscale RGD clustering. J. Cell Sci. 2000, 113, 1677-1686. [CrossRef] [PubMed]

10. Dalby, M.J.; Riehle, M.O.; Sutherland, D.S.; Agheli, H.; Curtis, A.S.G. Use of nanotopography to study mechanotransduction in fibroblasts-Methods and perspectives. Eur. J. Cell Biol. 2004, 83, 159-169. [CrossRef] [PubMed]

11. Nelson, C.M.; Jean, R.P.; Tan, J.L.; Liu, W.F.; Sniadecki, N.J.; Spector, A.A.; Chen, C.S. Emergent patterns of growth controlled by multicellular form and mechanics. Proc. Natl. Acad. Sci. USA 2005, 102, 11594-11599. [CrossRef]

12. Gorfinkiel, N.; Blanchard, G.B.; Adams, R.J.; Arias, A.M. Mechanical control of global cell behavior during dorsal closure in Drosophila. Development 2009, 136, 1889-1898. [CrossRef] [PubMed]

13. Mammoto, T.; Ingber, D.E. Mechanical control of tissue and organ development. Development 2010, 137, 1407-1420. [CrossRef] [PubMed]

14. Kumar, S.; Weaver, V.M. Mechanics, malignancy, and metatasis: The force journey of a tumor cell. Cancer Matastasis Rev. 2009, 28, 113-127. [CrossRef]

15. Paszek, M.J.; Zahir, N.; Johnson, K.R.; Lakins, J.N.; Rozenberg, G.I.; Gefen, A.; Reinhart-King, C.A.; Margulies, S.S.; Dembo, M.; Boettiger, D.; et al. Tensional homeostasis and the malignant phenotype. Cancer Cell 2005, 8, 241-254. [CrossRef]

16. Chen, C.S.; Mrksich, M.; Huang, S.; Whitesides, G.M.; Ingber, D.E. Geometric control of cell life and death. Science 1997, 276, 1425-1428. [CrossRef]

17. Chrzanowska-Wodicka, M.; Burridge, K. Rho-stimulated contractility drives the formation of stress fibers and focal adhesions. J Cell Biol. 1996, 133, 1403-1415. [CrossRef] [PubMed]

18. Folkman, J.; Moscona, A. Role of cell shape in growth control. Nature 1978, 273, 354-359. [CrossRef]

19. Fenteany, G.; Janmey, P.A.; Stossel, T.P. Signaling pathways and cell mechanics involved in wound closure by epithelial cell sheets. Curr. Biol. 2000, 10, 831-838. [CrossRef]

20. Bruguès, A.; Ester, A.; Conte, V.; Veldhuis, J.H.; Gupta, M.; Colombelli, J.; Munoz, J.J.; Brodland, G.W.; Ladoux, B.; Trepat, X. Forces driving epithelial wound healing. Nat. Phys. 2014, 10, 683-690.

21. Balaban, N.Q.; Schwarz, U.S.; Riveline, D.; Goichberg, P.; Tzur, G.; Sabanay, D.; Mahalu, S.; Safran, S.; Bershadsky, A.; Addadi, L.; et al. Force and focal adhesion: A close relationship studied using elastic micropatterned substrates. Nat. Cell Biol. 2001, 2, 466-472. [CrossRef] [PubMed]

22. Beningo, K.A.; Dembro, M.; Kaverina, I.; Small, J.V.; Wang, Y.L. Nascent focal adhesions are responsible for the generation of strong propulsive forces in migrating fibroblasts. J. Cell Biol. 2001, 153, 881-888. [CrossRef]

23. Bershadsky, A.D.; Balaban, N.Q.; Geiger, B. Adhesion-dependent cell mechanosensitivity. Annu. Cell Dev. Biol. 2003, 19, 677-695. [CrossRef]

24. Geiger, B.; Spatz, J.P.; Bershadsky, A.D. Environmental sensing through focal adhesions. Nat. Rev. Mol. Cell Biol. 2009, 10, 21-33. [CrossRef] [PubMed]

25. Winograd-Katz, S.E.; Fassier, R.; Geiger, R.; Legate, K.R. The integrin adhesome: From genes and proteins to human disease. Nat. Rev. Mol. Cell Biol. 2014, 15, 273-288. [CrossRef] [PubMed]

26. Maartens, A.P.; Brown, N.H. Anchors and signals: The diverse roles of integrins in development. Curr. Top. Dev. Biol. 2015, 112, 233-272.

27. Horton, E.R.; Humphries, J.D.; James, J.D.; Jones, M.C.; Askari, J.A.; Humphries, M.J. The integrin adhessome at a glance. J. Cell Sci. 2016, 129, 4159-4163.

28. Zaidel-Bar, R.; Itzkovitz, S.; Ma'ayan, A.; Iyengar, R.; Geiger, B. Functional atlas of the integrin adesome. Nat. Cell Biol. 2007, 9, 858-867. [CrossRef]

29. Roca-Cusachs, P.; Iskratsch, T.; Sheetz, M.P. Finding the weakest link-Exploring integrin-mediated mechanical molecular pathways. J. Cell Biol. 2012, 125, 3025-3038. [CrossRef]

30. Klapholz, B.; Brown, N.H. Talin-The master of integrin adhesions. J. Cell Sci. 2017, 130, 2435-2446. [CrossRef] [PubMed]

31. Atherton, P.; Sttchbury, B.; Wang, D.Y.; Jethwa, D.; Tsang, R.; Meiler-Rodriqhez, E.; Wang, P.; Bate, N.; Zent, R.; Barsukov, I.L.; et al. Vinculin controls talin engagement with the actomyosin machinery. Nat. Commun. 2015, 6, 10038. [CrossRef]

32. Changede, R.; Xu, X.; Margadant, F.; Sheetz, M.P. Nascent integrin adhesions form on all matrix rigidities after integrin activation. Dev. Cell 2015, 35, 614-621. [CrossRef] [PubMed]

33. Changede, R.; Sheetz, M. Integrin and cadherin clusters: A robust way to organize adhesions foe cell mechanics. Bioessays 2016, 39, 1-12. [CrossRef]

34. Choi, C.K.; Vicente-Manzanares, M.; Zareno, J.; Whitmore, L.A.; Mogilner, A.; Horwitz, A.R. Actin and $\alpha$-actinin orchestrate the assembly anf maturation of nascent adhesions in a myosin II motor-independent manner. Nat. Cell Biol. 2008, 10, 1039-1050. [CrossRef]

35. Sun, Z.; Costell, M.; Fässler, R. Integrin activation by talin, kindlin and mechanical forces. Nat. Cell Biol. 2019, 21, 25-31. [CrossRef] [PubMed]

36. Cluzel, C.; Saltel, F.; Lussi, J.; Paulhe, F.; Imhof, B.A.; Wehrle-Haller, B. The mechanisms and dynamics of $\alpha$ v $\beta 3$ integrin clustering in livibg cells. J. Cell Biol. 2005, 171, 383-392. [CrossRef] [PubMed] 
37. Schvartzman, M.; Palma, M.; Sable, J.; Abramson, J.; Hu, X.; Sheetz, M.P.; Wind, S.J. Nanolithographic control of the spatial organization of cellular adhesion receptors at the single-molecule level. Nano Lett. 2011, 11, 1306-1312. [CrossRef]

38. Cavalcanti-Adam, E.A.; Aydin, D.; Hirechfeld-Warneken, V.C.; Spatz, J.P. Cell adhesion and response to synthetic nanopatterned environments by steering clustering and spatial location. HFSP J. 2006, 2, 276-285. [CrossRef]

39. Ballestram, C.; Hinz, B.; Imhof, B.E.; Wehrle-Haller, B. Marching at the front and dragging behind: Differential $\alpha \mathrm{V} \beta 3$-integrin turnover regulates focal adhesion behavior. J. Cell Biol. 2001, 155, 1319-1332. [CrossRef]

40. Kucik, D.F. Rearrangement of integrins in avidity regulation by leukocytes. Immunol. Res. 2002, 26, 199-206. [CrossRef]

41. Martino, F.; Perestrelo, A.R.; Vinarsky, V.; Pagliari, S.; Forte, G. Cellular mechanotranduction: From tension to function. Front. Physiol. 2018, 9, 824. [CrossRef]

42. Wolfenson, H.; Yang, B.; Sheetz, M.P. Steps in mechanotransduction pathways that control cell morphology. Annu. Rev. Physiol. 2019, 81, 585-605. [CrossRef]

43. Dorland, Y.L.; Huveneers, S. Cell-cell junctional mechanotransduction in endothelial remodeling. Cell. Mol. Life Sci. 2017, 74, 279-292. [CrossRef]

44. Kanyo, N.; Kovacs, K.D.; Saftics, A.; Szekacs, I.; Peter, B.; Santa-Maria, A.R.; Walter, F.R.; Dér, A.; Horvath, R. Glycocalyx regulates the strength and kinetics of cancer cell adhesion revealed by viophysical models based on high resolution label-free optical data. Sci. Rep. 2020, 10, 22422. [CrossRef]

45. Shattil, S.J.; Kim, C.; Ginsberg, M.H. The final steps of integrin activation: The end game. Nat. Rev. Mol. Cell Biol. 2010, 11, 288-300. [CrossRef]

46. Calderwood, D.R.; Zent, R.; Grant, R.; Jasper, D.; Rees, G.; Hynes, R.O.; Ginsberg, M.H. The talin head domain binds to integrin $\beta$ subunit cytoplasmic tails and regulates integrin activation. J. Biol. Chem. 1999, 274, 28071-28074. [CrossRef] [PubMed]

47. Garcia-Alvarez, B.; de Pereda, J.M.; Calderwood, D.A.; Ulmer, T.S.; Critchley, D.A.; Campbell, I.D.; Ginsberg, M.H.; Liddington, R.C. Structural determinants of integrin recognition by talin. Mol. Cell 2003, 11, 49-58. [CrossRef]

48. Ye, F.; Hu, G.; Taylor, D.; Ratnikov, B.; Bobkov, A.A.; McLean, M.A.; Sligar, S.G.; Taylor, K.A.; Ginsberg, M.H. Recreation of the terminal events in physilogical integrin activation. J. Cell Biol. 2010, 188, 157-173. [CrossRef] [PubMed]

49. Calderwood, D.A.; Campbell, I.D.; Critchley, D.R. Talin and kindlins: Partners in integrin-mediated adhesion. Nat. Rev. Mol. Biol. 2013, 14, 503-517. [CrossRef] [PubMed]

50. Carman, C.V.; Springer, T.A. Integrin avidity regulation: Are changes in affinity and conformation underemphasized? Curr. Opin. Cell Biol. 2003, 15, 547-556. [CrossRef] [PubMed]

51. Li, J.; Su, Y.; Xia, W.; Humphries, M.J.; Vestweber, D.; Cabañs, C.; Lu, C.; Springer, T.A. Conformational equlibria and intrinsic affinities define integrin activation. EMBO J. 2017, 36, 629-645. [CrossRef] [PubMed]

52. Calderwood, D.A. Talin controls integrin activation. Biochem. Soc. Trans. 2004, 32, 434-437. [CrossRef]

53. Kim, C.; Ye, F.; Xiaohui, H.; Ginsberg, M.H. Talin activates integrins by altering the topology of the $\beta$ transmembrane domain. J. Cell Biol. 2011, 197, 605-611. [CrossRef]

54. Ginsberg, M.H. Integrin Activation. BMB Rep. 2014, 47, 655-659. [CrossRef]

55. Du, X.; Gu, M.; Weisel, J.W.; Nagaswami, C.; Bennett, J.S.; Bowditch, R.; Ginsberg, M.H. Long range propagation of conformational changes in integrin $\alpha_{I I I} \beta_{3}$. J. Biol. Chem. 1993, 268, 23087-23092. [CrossRef]

56. Theodosiou, M.; Widmaier, M.; Börrcher, R.T.; Rognoni, E.; Veeiders, M.; Bharadwaj, M.; Lambacher, A.; Austen, K.; Muller, D.J.; Zent, R.; et al. Kindlin-2 cooperates with talin to activate integrins and induces cell spreading by directly binding paxillin. eLife 2016, 5, e10130. [CrossRef]

57. Saltel, F.; Martier, E.; Hytönen, V.P.; Jacqier, M.C.; Zimmermann, P.; Vogel, V.; Liu, W.; Wehrle-Haller, B. New PI (4, 5) P2-and membrane proximal integrin-binding motifs in the talin head control $\beta 3$-integrin clustering. J. Cell Biol. 2009, 187, 715-731. [CrossRef] [PubMed]

58. Reynwar, B.; Illya, G.; Hamandaris, V.A.; Muller, M.M.; Krermer, K.; Deserno, M. Aggregation and vesiculation of membrane proteins by curvature-mediated interactions. Nature 2007, 447, 461-464. [CrossRef]

59. Reynwar, B.; Deserno, M. Membrane-mediated interactions between circular particles in strongly curved regieme. Soft Matter 2011, 7, 8567. [CrossRef]

60. Van der Wel, C.; Vahid, A.; S̆arić, A.; Idema, T.; Heinrich, D.; Kraft, D.J. Lipid membrane-mediated attraction between curvature inducing objects. Sci. Rep. 2016, 6, 32825-32834. [CrossRef] [PubMed]

61. Gingras, A.R.; Ginsberg, M.H. Signal transduction: Physical deformation of the membrane activates integrins. Curr. Biol. 2020, 30, R397-R400. [CrossRef]

62. Chen, X.; Xie, C.; Nishida, N.; Li, Z.; Walz, T.; Springer, T.A. Requirement of open headpiece conformation for activation of leukocyte integrin $\alpha_{x} \beta_{2}$. Proc. Natl. Acad. Sci. USA 2010, 107, 14727-14732. [CrossRef] [PubMed]

63. Kim, J.; Lee, J.; Jang, J.; Ye, F.; Hong, S.J.; Petrich, B.G.; Ulmer, T.S.; Kim, C. Toplological adaptation of transmembrane domains to force-modulated lipid bilayer is a basis of sensing mechanical force. Curr. Biol. 2020, 30, 1614-1625. [CrossRef]

64. Son, S. The Role of Membrane in Integrin-Mediated Adhesion of Cells to Surfaces. Ph.D. Thesis, Penn State University, State College, PA, USA, 2018

65. Kammerer, P.; Aretz, J.; Fässler, R. Lucky kindlin: A cloverleaf at the integrin tail. Proc. Natl. Acad. Sci. USA 2017, 114, 234-236. [CrossRef] 
66. Bachir, A.; Zareno, J.; Moissoglu, K.; Plow, E.; Gratton, E.; Horwitz, A.R. Integrin-associated complexes form hierarchically with variable stochiometry during nascent adhesion formation. Curr. Biol. 2014, 24, 1845-1853. [CrossRef]

67. Johnson, K.L. Contact Mechanics; Cambridge University Press: New York, NY, USA, 2003.

68. Goennenwein, G.; Tanaka, M.; Hu, B.; Moroder, L.; Sackmann, E. Functional incorporation of integrins into solid supported membranes on unltrathin films of cellulose: Impact on adhesion. Biophys. J. 2003, 85, 646-655. [CrossRef]

69. Bagi, Z.; Couch, Y.; Broskova, Z.; Perez-Balderas, F.; Yeo, T.; Davis, S.; Fischer, R.; Sibson, N.R.; Davis, B.G.; Anthony, D.C. Extracellular vesicle integrins act as a nexus for platelet adhesion in cerebral microvessels. Sci. Rep. 2019, 9, 15847. [CrossRef]

70. Heitjans, P.; Kärger, J. Diffusion in Condensed Matter; Springer: Heidelberg, Germany, 2005.

71. Brànka, A.C.; Heyes, D.M. Algorithms for Brownian dynamics computer simulations: Multivariable case. Phys. Rev. E 1999, 60, 2381-2387. [CrossRef]

72. Sun, L.; Cheng, Q.H.; Gao, H.; Zhang, Y.W. Computational modeling for cell spreading on a substrate mediated by specific interactions, long-range recruiting interactions, and diffusion of binders. Phys. Rev. E 2009, 79, 061907. [CrossRef] [PubMed]

73. Erdmann, T.; Schwarz, U.S. Stochastic dynamics of adhesion clusters under shared constant force and with rebinding. J. Chem. Phys. Lett. 2004, 121, 8997-9017. [CrossRef] [PubMed]

74. Bell, G.I. Models for the specific adhesion of cells to cells. Science 1978, 200, 618-627. [CrossRef]

75. Bell, G.I.; Dembro, M.; Bongrand, P. Competition between nonspecific and specific bonding. Biophys. J. 1984, 45, 1051-1064. [CrossRef]

76. Dembo, M.; Torney, D.C.; Saxaman, K.; Hammer, D.A. The reaction-limited kinetics of membrane-to-surface adhesion and detachment. Proc. R. Soc. Lond. B 1988, 234, 55-83.

77. Thomas, W.; Forero, M.; Yakovenko, O.; Nilsson, L.; Vicini, P.; Sokurenko, E.; Vogel, V. Catch-bond model derived from allostery explains force-activated bacterial adhesion. Biophys. J. 2006, 90, 753-764. [CrossRef]

78. Thomas, W. Catch bond in adhesion. Annu. Rev. Biomed. Eng. 2008, 10, 39-57. [CrossRef] [PubMed]

79. Asaro, R.J.; Lin, K.; Zhu, Q. Mechanosensitivity occurs along the adhesome's force train and affects traction stress. Biophys. J. 2019, 117, 1599-1614. [CrossRef]

80. Paszek, M.J.; Boettiger, D.; Weaver, V.M.; Hammer, D.A. Integrin clustering is driven by mechanical resistence from the glycocalyx and the substrate. PLoS Comput. Biol. 2009, 5, e10000604. [CrossRef]

81. Sun, L.; Cheng, Q.H.; Gao, H.J.; Zhang, Y.W. Effect of loading conditions on the dissociation behavior of catch bond clusters. J. R. Soc. Interface 2011, 9, 928-937. [CrossRef]

82. Paszek, M.J.; DuFort, C.C.; Rossier, O.; Bainer, R.; Mouw, J.K.; Godula, K.; Hudak, J.E.; Lakins, J.N.; Wijekoon, A.C.; Cassereau, L.; et al. The cancer glycocalyx mechaincally primes integrin-mediated growth and survival. Nature 2014, 511, 319-324. [CrossRef]

83. Qian, J.; Gao, H. Soft matrices suppress cooperation behaviors among receptor-ligand bonds in cell adhesions. PLoS ONE 2010, 5, e12342. [CrossRef] [PubMed]

84. Erdmann, T.; Schwartz, U.S. Stability of adhesion clusters under constant force. Phys. Rev. Lett. 2004, 92, 108102. [CrossRef]

85. Luo, B.H.; Strokovich, K.; Walz, T.; Springer, T.A. Allosteric $\beta_{1}$ integrin antibodies that stabilize the low affinity state by preventing the swingout of the hybrid domain. J. Biol. Chem. 2004, 279, 27466-27471. [CrossRef]

86. Alberts, B.; Johnson, A.; Lewis, J.; Raff, M.; Roberts, K.; Walter, P. Molecular Biology of the Cell; Garland Science: New York, NY, USA, 2002.

87. Weinbaum, S.; Tarbell, J.M.; Damiano, E.R. The structure and function of the endothelial glycocalyx. Annu. Rev. Biomed. Eng. 2007, 9, 121-167. [CrossRef]

88. Soler, J.M.; Desplat-Jego, S.; Vacher, B.; Ponsonnet, L.; Fraterno, M.; Bongrand, P.; Martin, J.-M.; Foa, C. Adhesion-related glycocalyx study: Quantitative approach with imaging-spectrum in the energy filtering transmission microscope (EFTEM). FEBS Lett. 1998, 429, 89-94. [CrossRef]

89. Squire, J.M.; Chew, M.; Nneji, G.; Neal, C.; Barry, J.; Michel, C. Quasi-periodic substructure in the microvessel endothelial glycocalyx: A possible explanation for molecular filtering. J. Struct. Biol. 2001, 136, 239-255. [CrossRef] [PubMed]

90. Lepzeiter, D.; Zaman, M.H. Clustered diffusion of integrins. Biophys. J. 2010, 99, L106-L108. [CrossRef] [PubMed]

91. Bakker, G.J.; Eich, C.; Torreno-Pina, J.A.; Diez-Ahedo, R.; Perez-Samper, G.; van Zanten, T.S.; Figdor, C.G.; Cambi, A.; GarciaParajo, M.F. Lateral mobility of individual integrin nanoclusters orchestrates the onset for leukocyte adhesion. Proc. Natl. Acad. Sci. USA 2012, 109, 4869-4874. [CrossRef]

92. Yauch, R.L.; Felsenfeld, D.P.; Kraeft, S.K.; Chen, L.B.; Sheetz, M.P.; Hemler, M.E. Mutational evidence for control of adhesion through diffusion/Clustering Independent of ligand binding. J. Exp. Med. 1997, 186, 1347-1355. [CrossRef] [PubMed]

93. Rossier, O.; Octaeu, V.; Sibarita, J.-B.; Leduc, C.; Tessier, B.; Nair, D.; Gatterdam, V.; Destaing, O.; Albiges-Rizo, C.; Tampe, R.; et al. Integrins $\beta_{1} \beta_{3}$ exhibit distinct dynamic nanoscale organizations inside focal adhesions. Nat. Cell Biol. 2012, 14, 1057-1068. [CrossRef]

94. Chang, B.H.; Bae, Y.C. Salting out in the aqeous single-protein solution: The effect of shape factor. Biophys. Chem. 2003, 104, 523-533. [CrossRef]

95. Docherty, H.; Galindo, A.; Sanz, E.; Vega, C. Investigation of the slating out of methane from aqueous electrolyte solutions using computer simulations. J. Phys. Chem. 2007, 111, 8993-9000. [CrossRef] [PubMed] 